\title{
Five years of exercise intervention at different intensities and development of white matter hyperintensities in community dwelling older adults, a Generation 100 sub-study
}

\author{
Anette Arild1, Torgil Vangberg, ${ }^{2,3}$, Hanne Nikkels4, Stian Lydersen ${ }^{5}$, Ulrik Wisløff6,7, Dorthe \\ Stensvold $^{6,7}$, Asta K. Håberg ${ }^{1,4}$ \\ ${ }^{1}$ Department of Neuromedicine and Movement Science, Faculty of Medicine and Health Sciences, NTNU \\ Norwegian University of Science and Technology, Trondheim, Norway \\ ${ }^{2}$ Department of Clinical Medicine, Faculty of Health Sciences, UiT The Arctic University of Norway, Troms $\varnothing$, Norway \\ ${ }^{3}$ PET Center, University Hospital of North Norway, Troms $\varnothing$, Norway \\ ${ }^{4}$ Department of Radiology and Nuclear Medicine, St. Olavs Hospital, Trondheim University Hospital, Trondheim, \\ Norway \\ ${ }^{5}$ Department of Mental Health, Faculty of Medicine and Health Sciences, NTNU Norwegian University of Science \\ and Technology, Trondheim, Norway \\ ${ }^{6}$ Department of Circulation and Medical Imaging, Faculty of Medicine and Health Sciences, NTNU Norwegian \\ University of Science and Technology, Trondheim, Norway \\ ${ }^{7}$ Department of Cardiology, St. Olavs Hospital, Trondheim University Hospital, Trondheim, Norway
}

Correspondence to: Asta K. Håberg; email: asta.haberg@ntnu.no

Keywords: leukoaraiosis, senior, physical fitness, prospective, randomized controlled trial

Received: November 19, 2021 Accepted: January 4, $2022 \quad$ Published: January 18, 2022

Copyright: (C) 2022 Arild et al. This is an open access article distributed under the terms of the Creative Commons Attribution License (CC BY 3.0), which permits unrestricted use, distribution, and reproduction in any medium, provided the original author and source are credited.

\section{ABSTRACT}

We investigated if a five-year supervised exercise intervention with moderate-intensity continuous training (MICT) or high-intensity interval training (HIIT) versus control; physical activity according to national guidelines, attenuated the growth of white matter hyperintensities (WMH). We hypothesized that supervised exercise, in particular HIIT, reduced WMH growth. Older adults from the general population participating in the RCT Generation 100 Study were scanned at 3T MRI at baseline (age 70-77), and after 1-, 3- and 5-years. At each follow-up, cardiorespiratory fitness was measured with ergospirometry, and physical activity plus clinical data collected. Manually delineated total WMH, periventricular (PWMH), deep (DWMH), and automated total white matter hypointensity volumes were obtained. No group by time interactions were present in linear mixed model analyses with the different WMH measurements as outcomes. In the combined exercise (MICT\&HIIT) group, a significant group by time interaction was uncovered for PWMH volume, with a larger increase in the MICT\&HIIT group. Cardiorespiratory fitness at the follow-ups or change in cardiorespiratory fitness over time were not associated with any WMH measure. Contrary to our hypothesis, taking part in MICT or HIIT over a five-year period did not attenuate WMH growth compared to being in a control group following national physical activity guidelines.

\section{INTRODUCTION}

White matter hyperintensities (WMH), also known as leukoaraiosis, are the most common finding on brain
MRI in persons aged 50 and older $[1,2]$. Its presence is associated with functional impairments such as gait disturbance [3, 4] and cognitive decline [5], as well as diseases such as depression [6], stroke and dementia [7]. 
WMH appear as hyperintense areas in the brain on T2-weighted MRI scans, e.g., fluid-attenuated inversion recovery (FLAIR), and are usually symmetrically distributed around the ventricles (periventricular $\mathrm{WMH}$, PWMH) and in the deep white matter (deep WMH, DWMH). PWMH and DWMH are associated with overlapping as well as unique genetic markers [8], etiologies [9, 10], and clinical correlates [11, 12], leading to the two subdivisions being regarded as different entities [13]. Even though WMH have a clinical impact in old age and several risk factors are identified [14-16], there is no consensus as to how to treat or reduce them.

Observational studies suggest that physical activity and exercise may limit WMH. Two systematic reviews found physical activity to be associated with less $\mathrm{WMH}[17,18]$, and the effect appeared particularly prominent in older adults $[19,20]$. Both participating in physical activity and aerobic exercise training can improve cardiorespiratory fitness, which is suggested as a central mechanism for the effect of training on the brain [21]. Still, three recent intervention studies did not uncover a positive effect of 6-24 months of physical activity, aerobic exercise or multimodal lifestyle intervention compared to usual care or general life-style advice [22-24]. Intervention studies with more intense exercise aimed at maximizing cardiovascular fitness, longer intervention periods with several follow-ups to monitor change over time in both $\mathrm{WMH}$ and fitness, and objective measures of cardiovascular fitness, i.e., $\mathrm{VO}_{2 \text { peak }}$ measured during ergospirometry, are suggested to resolve the current conundrum $[17,25,26]$. Since physical activity appears to limit WMH growth most effectively in older adults, this group is a highly relevant target group for exercise intervention studies.

In a sub-study of the randomized controlled trial (RCT) Generation 100 Study in adults born between 1936 and 1942 [27, 28], we investigated the evolution of WMH on brain MRI acquired at $3 \mathrm{~T}$ at baseline, and after one, three, and five years of supervised exercise with either moderate-intensity continuous training (MICT) or highintensity interval training (HIIT) compared to a control group that followed the Norwegian national recommendations for physical activity.

We hypothesized that manually derived $\mathrm{WMH}$ volume would grow less in the supervised training groups, particularly in the HIIT group, compared to the control group, and that a greater gain in $\mathrm{VO}_{2 \text { peak }}$ would translate to attenuated WMH growth. Since there is increased use of automated methods for WMH delineation, analyses with both the gold standard manual and an automated method were performed.

\section{RESULTS}

\section{Participants and participation}

In total, 105 MRI participants were included and scanned at baseline. After five years, 85 participants remained in the study, none of whom were diagnosed with MCI or dementia. Participants who withdrew from the study, did so mainly during the first year. Two participants died of cancer in the HIIT group during the study. See Figure 1 for an overview of participants at each timepoint and MRI scans passing quality assessment and included in statistical analysis. For variables used in this paper, data were missing completely at random $\left(X^{2}(1737)=1747.66, p=0.42\right)$.

The results of the baseline comparisons of demographic and clinical characteristics of those participating and not participating in the MRI sub-study are displayed in Table 1. Participants participating in the MRI sub-study had a higher level of education, $\mathrm{VO}_{2 \text { peak }}$ was on average $1.7 \mathrm{~mL} / \mathrm{kg} / \mathrm{min}$ higher, and Hospital Anxiety and Depression Scale (HADS) scores were lower than in the group not scanned. There were also minimal though significant differences in age and blood fat values, with the participants with MRI having lower triglycerides (median 0.93 vs. $1.01 \mathrm{mmol} / \mathrm{L}$ ) and higher $\mathrm{HDL}$ (median 1.74 vs. $1.66 \mathrm{mmol} / \mathrm{L}$ ) levels.

The baseline and the five-year demographic, clinical and $\mathrm{VO}_{2 \text { peak }}$ characteristics of the control, MICT and HIIT group participants in the MRI study are shown in Table 2. There were no differences between the three groups at baseline or after five years (Table 2A and 2B).

During the supervised exercise sessions, the HIIT group trained on average at $88 \%$ of peak heart rate and at an intensity of 16.9 on the Borg scale, while the MICT group trained at $73 \%$ of peak heart rate with a mean intensity of 13.8 on the Borg scale.

During the intervention period, $\mathrm{VO}_{2 \text { peak }}$ increased significantly and similarly in all groups from baseline to one-year follow-up (estimate: $2.3,95 \%$ CI 1.1 to 3.4, $p$-value <0.001) (Figure 2), and then declined to baseline levels at the five-year follow-up (not significant). There was no effect of group or group*time interaction on $\mathrm{VO}_{2 \text { peak. }}$.

Based on the questionnaires, adherence to the allocated physical activity or exercise program was good, ranging between $71.4 \%$ and $94.3 \%$ across the groups throughout the intervention (Table 3). Furthermore, participants in the HIIT group exercised at a significantly higher intensity level than both MICT and controls at all timepoints during the five-year intervention period, but 
exercise frequency and session duration were similar across the three groups at all timepoints (Table 4). The types of activities varied between the control, MICT and HIIT groups, with the HIIT group biking more the first year, swimming more at year three, and training more at fitness centers at year five than the other groups (Table 5).

\section{White matter hyperintensities}

For the manual WMH volumes, the intra-rater reliability calculated with ICC was $0.99(95 \% \mathrm{CI}=$ 0.99 to 1.00$)$ for rater 1 and $0.99(95 \% \mathrm{CI}=0.96$ to 1.00) for rater 2 indicating excellent agreement. The inter-rater reliability, evaluated in a longitudinal linear mixed model analysis, showed a significant association between WMH and WM-hypointensity volume (estimate $=0.19,95 \% \mathrm{CI}=0.15$ to $0.22, p<$ 0.001 ) while no interaction was present between rater and $\mathrm{WMH}$ volume (estimate $=0.01,95 \% \mathrm{CI}=-0.02$ to $0.05, p=0.486)$. Additionally, rater was not associated with WM-hypointensity volume (estimate =
$-0.19,95 \% \mathrm{CI}=-0.76$ to $0.37, p=0.503)$. Thus, the inter-rater analysis indicated a similar association between both raters and WMH and WM-hypointensity volumes.

Figure 2 shows the development in WMH volume over time for all participants. The WMH volume varied between participants at baseline (lowest volume: 0, highest volume: $36 \%$ of ICV) and increased over time. Table 6 shows WMH, PWMH, DWMH and WMhypointensity volumes at each timepoint during the intervention period. See Tables 7 and 8 for statistical evaluations of time and age effects.

\section{Intervention results}

The linear mixed model investigating the effect of MICT and HIIT compared to the control condition on WMH volume during the five-year RCT did not reveal an interaction between group and time on $\mathrm{WMH}$ volume (Table 7). Only time at five years was significantly positively associated with WMH volume. Similar results

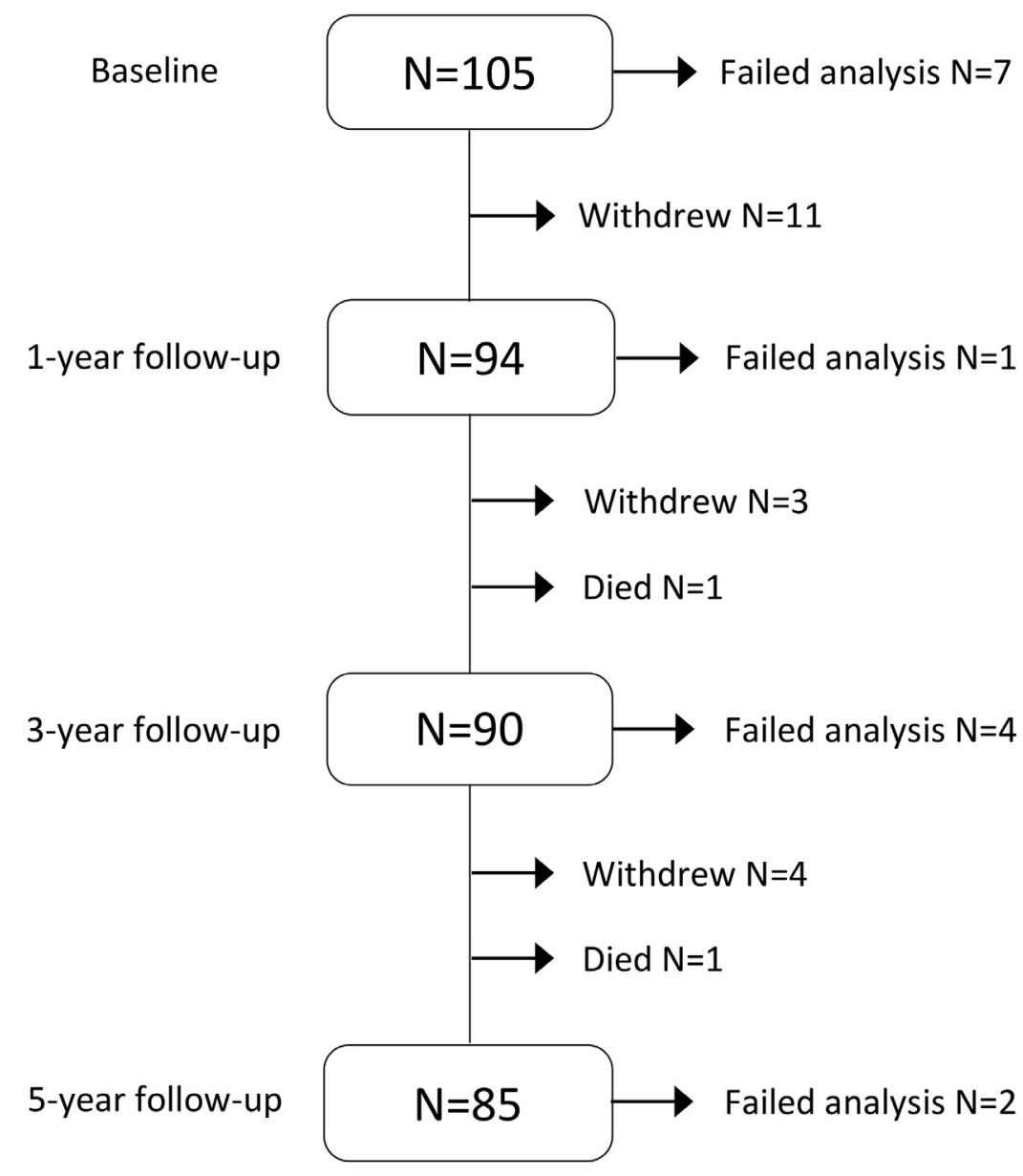

Figure 1. Flowchart of participation, attrition and MRI data included in statistical analysis during the five-year intervention. Failed analysis included corrupted images, motion or other artifacts interfering with manual delineation and/or automated analysis (Figures 3 and 4). 
Table 1. Demographic and clinical characteristics at baseline of participants in the RCT Generation 100 (G100) study taking and not taking part in the neuroimaging study.

\begin{tabular}{|c|c|c|c|}
\hline & $\begin{array}{c}\text { G100 without MRI } \\
(N=1461)\end{array}$ & $\begin{array}{c}\text { G100 with MRI } \\
(N=105)\end{array}$ & $p$-value \\
\hline Age $^{\text {a }}$ (years) & $72.6(3.2)$ & $72.2(2.6)$ & 0.045 \\
\hline Women $^{\mathrm{b}}(\%)$ & 50.5 & 49.5 & 0.845 \\
\hline Education $^{\mathrm{a}}(\%)$ & & & 0.003 \\
\hline Primary school & 15.3 & 8.7 & \\
\hline High school & 35.2 & 26.9 & \\
\hline University & 49.5 & 64.4 & \\
\hline Living alone $(\%)$ & 24.8 & 29.8 & 0.253 \\
\hline Current smoker ${ }^{b}(\%)$ & 8.5 & 8.7 & 0.944 \\
\hline Pack years ${ }^{\mathrm{a}, \mathrm{c}}$ & $13.7(18)$ & $11.3(17)$ & 0.246 \\
\hline Hypertension $^{\mathrm{b}, \mathrm{d}}(\%)$ & 55.9 & 49.0 & 0.179 \\
\hline Diabetes $^{\mathrm{b}, \mathrm{e}}(\%)$ & 8.6 & 4.7 & 0.160 \\
\hline Waist circumference ${ }^{\mathrm{f}}(\mathrm{cm})$ & $94.2(11.1)$ & $93.7(10.6)$ & 0.639 \\
\hline Body mass index ${ }^{\mathrm{f}}\left(\mathrm{kg} / \mathrm{m}^{2}\right)$ & $26.0(3.6)$ & $25.9(3.3)$ & 0.848 \\
\hline Triglycerides $^{\mathrm{a}}(\mathrm{mmol} / \mathrm{L})$ & $1.0(0.6)$ & $0.9(0.5)$ & $\mathbf{0 . 0 3 2}$ \\
\hline $\mathrm{LDL}^{\mathrm{a}}(\mathrm{mmol} / \mathrm{L})$ & $3.4(1.4)$ & $3.3(1.5)$ & 0.621 \\
\hline $\mathrm{HDL}^{\mathrm{a}}(\mathrm{mmol} / \mathrm{L})$ & $1.7(0.7)$ & $1.7(0.7)$ & 0.043 \\
\hline Total cholesterol ${ }^{f}(\mathrm{mmol} / \mathrm{L})$ & $5.6(1.1)$ & $5.8(1.0)$ & 0.246 \\
\hline hsCRP (mg/L) $)^{a}$ & $1.3(1.8)$ & $1.2(1.6)$ & 0.379 \\
\hline $\mathrm{VO}_{2 \text { peak }} \mathrm{f}(\mathrm{mL} / \mathrm{kg} / \mathrm{min})$ & $28.6(6.4)$ & $30.3(6.4)$ & 0.012 \\
\hline Testing on bikeg $(\%)$ & 3.0 & 2.9 & 1.000 \\
\hline Reached $\mathrm{VO}_{2 \max } \mathrm{b}(\%)$ & 59.9 & 65.4 & 0.269 \\
\hline HADS $^{\text {f }}$ (total score) & $6.2(4.4)$ & $4.6(3.6)$ & $<0.001$ \\
\hline
\end{tabular}

${ }^{a}$ Mann-Whitney $U$-test (percentage or median and interquartile range (IQR)); ${ }^{b}$ Chi-square (percentage); ${ }^{\text {cPack }}$ year: 20 cigarettes daily for one year; ${ }^{d}$ Hypertension: SBP $\geq 140 \mathrm{mmHg}$ and/or DBP $\geq 90 \mathrm{mmHg}$ and/or use of blood pressure medication; 'Diabetes: fasting p-glucose $\geq 7.0 \mathrm{mmol} / \mathrm{L}$ and/or $\mathrm{HbA1c} \geq 48 \mathrm{mmol} / \mathrm{mol}$ and/or diagnosed (type 1 or type 2). fIndependent $t$-test (mean and standard deviation (SD)); ${ }^{\mathrm{F} F i s c h e r ' s ~ e x a c t ~(p e r c e n t a g e) . ~ A b b r e v i a t i o n s: ~ G 100: ~ G e n e r a t i o n ~ 100 ; ~}$ LDL: low-density lipoprotein; HDL: high-density lipoprotein; hSCRP: high-sensitive C-reactive protein; SBP: systolic blood

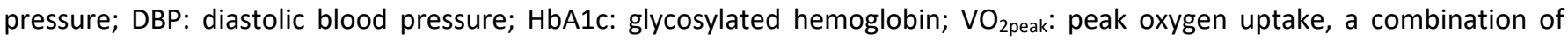
$\mathrm{VO}_{2 \max }$ and $\mathrm{VO}_{2 \text { peak }}$ values; $\mathrm{VO}_{2 \max }$ : maximal oxygen uptake; HADS: Hospital Anxiety and Depression Scale.

Table 2. Comparison of the control, moderate-intensity continuous training (MICT) and high-intensity interval training (HIIT) exercise groups at baseline (A) and after five years (B).

\begin{tabular}{|c|c|c|c|c|}
\hline \multicolumn{5}{|c|}{ A. Baseline characteristics } \\
\hline & $\begin{array}{l}\text { Control } \\
(N=48)\end{array}$ & $\begin{array}{c}\text { MICT } \\
(N=24)\end{array}$ & $\begin{array}{c}\text { HIIT } \\
(N=33)\end{array}$ & $p$-value \\
\hline Age $^{\mathrm{a}}$ (years) & $72.3(2.4)$ & $71.8(2.2)$ & $72.3(3.1)$ & 0.791 \\
\hline Women ${ }^{\mathrm{b}}(\%)$ & 52.1 & 54.2 & 42.4 & 0.607 \\
\hline Education $^{\mathrm{b}}(\%)$ & & & & 0.501 \\
\hline Primary school & 8.3 & 12.5 & 6.3 & \\
\hline High school & 33.3 & 20.8 & 21.9 & \\
\hline University & 58.3 & 66.7 & 71.9 & \\
\hline Living situation ${ }^{\mathrm{b}}(\%)$ & & & & 0.953 \\
\hline Alone & 31.3 & 29.2 & 28.1 & \\
\hline With partner & 68.8 & 70.8 & 71.9 & \\
\hline Current smoker' $(\%)$ & 10.4 & 4.3 & 9.4 & 0.817 \\
\hline Pack years ${ }^{\mathrm{a}, \mathrm{d}}$ & $9.8(11)$ & $18.5(40)$ & $13.8(23)$ & 0.330 \\
\hline Hypertension $^{\mathrm{b}, \mathrm{e}}(\%)$ & 50.0 & 47.8 & 45.2 & 0.915 \\
\hline Diabetes $^{\mathrm{c}, \mathrm{f}}(\%)$ & 2.1 & 8.7 & 6.5 & 0.432 \\
\hline Waist circumference $(\mathrm{cm})$ & $93.3(10.9)$ & $93.5(9.2)$ & $94.4(11.3)$ & 0.897 \\
\hline Body mass index ${ }^{\mathrm{g}}\left(\mathrm{kg} / \mathrm{m}^{2}\right)$ & $25.9(3.3)$ & $25.9(3.4)$ & $26.1(3.3)$ & 0.956 \\
\hline
\end{tabular}




\begin{tabular}{|c|c|c|c|c|}
\hline Triglycerides $^{\mathrm{a}}(\mathrm{mmol} / \mathrm{L})$ & $0.9(0.4)$ & $0.9(0.4)$ & $0.9(0.5)$ & 0.958 \\
\hline $\mathrm{LDL}^{\mathrm{a}}(\mathrm{mmol} / \mathrm{L})$ & $3.5(1.5)$ & $3.2(1.1)$ & $3.3(1.6)$ & 0.223 \\
\hline $\mathrm{HDL}^{\mathrm{a}}(\mathrm{mmol} / \mathrm{L})$ & $1.7(0.7)$ & $1.7(0.7)$ & $1.8(0.8)$ & 0.917 \\
\hline Total cholesterol $(\mathrm{mmol} / \mathrm{L})$ & $6.1(1.7)$ & $5.6(0.9)$ & $5.9(1.4)$ & 0.145 \\
\hline hsCRPa (mg/L) & $1.1(1.4)$ & $1.0(1.2)$ & $1.5(1.6)$ & 0.431 \\
\hline $\mathrm{VO}_{2 \text { peak }}{ }^{\mathrm{g}}(\mathrm{mL} / \mathrm{kg} / \mathrm{min})$ & $30.3(6.5)$ & $30.0(5.7)$ & $30.4(6.9)$ & 0.971 \\
\hline Testing on a bike $(\%)$ & 2.1 & 0.0 & 6.1 & 0.454 \\
\hline Reached $\mathrm{VO}_{2 \max } \mathrm{b}(\%)$ & 64.6 & 52.2 & 75.8 & 0.187 \\
\hline HADS $^{\text {a } \text { (total score) }}$ & $4(5)$ & $4(5)$ & $4(5)$ & 0.953 \\
\hline \multicolumn{5}{|c|}{ B. Follow up characteristics at five years } \\
\hline Age $^{\mathrm{a}}$ (years) & $76.8(2.2)$ & $77.2(1.9)$ & $77.4(3.2)$ & 0.841 \\
\hline Women $(\%)$ & 48.6 & 52.4 & 44.8 & 0.869 \\
\hline Education $(\%)$ & & & & 0.317 \\
\hline Primary school & 2.9 & 14.3 & 7.1 & \\
\hline High school & 31.4 & 14.3 & 17.9 & \\
\hline University & 65.7 & 71.4 & 75.0 & \\
\hline Living situation ${ }^{\mathrm{b}}(\%)$ & & & & 0.525 \\
\hline Alone & 35.3 & 21.1 & 26.9 & \\
\hline With partner & 64.7 & 78.9 & 73.1 & \\
\hline Current smoker $(\%)$ & 6.3 & 5.3 & 0.0 & 0.467 \\
\hline Hypertension ${ }^{\mathrm{b}, \mathrm{e}}(\%)$ & 64.5 & 44.4 & 52.0 & 0.362 \\
\hline Diabetes $^{\mathrm{c}, \mathrm{f}}(\%)$ & 0.0 & 11.8 & 8.7 & 0.110 \\
\hline Waist circumference $(\mathrm{cm})$ & $94.2(12.9)$ & $94.8(8.9)$ & $94.7(11.1)$ & 0.975 \\
\hline Body mass index ${ }^{\mathrm{g}}\left(\mathrm{kg} / \mathrm{m}^{2}\right)$ & $25.9(3.8)$ & $26.0(3.6)$ & $26.0(2.5)$ & 0.988 \\
\hline Triglycerides $^{\mathrm{a}}(\mathrm{mmol} / \mathrm{L})$ & $0.9(0.5)$ & $0.8(0.4)$ & $1.0(0.6)$ & 0.261 \\
\hline $\mathrm{LDL}^{\mathrm{g}}(\mathrm{mmol} / \mathrm{L})$ & $3.4(1.0)$ & $2.9(1.0)$ & $3.1(0.8)$ & 0.152 \\
\hline $\mathrm{HDL}^{\mathrm{a}}(\mathrm{mmol} / \mathrm{L})$ & $1.6(0.7)$ & $1.6(0.6)$ & $1.8(0.6)$ & 0.724 \\
\hline Total cholesterol ${ }^{\mathrm{g}}(\mathrm{mmol} / \mathrm{L})$ & $5.6(1.1)$ & $5.0(1.1)$ & $5.5(1.0)$ & 0.115 \\
\hline hsCRPa (mg/L) & $1.4(2.2)$ & $1.1(1.3)$ & $1.5(1.7)$ & 0.364 \\
\hline $\mathrm{VO}_{2 \text { peak }} \mathrm{g}(\mathrm{mL} / \mathrm{kg} / \mathrm{min})$ & $30.1(7.6)$ & $28.6(5.3)$ & $30.5(6.1)$ & 0.633 \\
\hline Testing on a bike $(\%)$ & 2.7 & 10.5 & 8.0 & 0.506 \\
\hline Reached $\mathrm{VO}_{2 \max } \mathrm{b}(\%)$ & 70.3 & 52.6 & 68.0 & 0.400 \\
\hline HADS $^{\text {a }}$ (total score) & $5(6)$ & $5(5)$ & $3(5)$ & 0.062 \\
\hline $\mathrm{MoCA}^{\mathrm{a}}$ (total score) & $26(4)$ & $27(3)$ & $27(3)$ & 0.270 \\
\hline
\end{tabular}

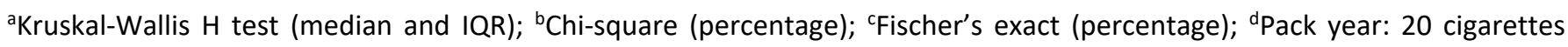
daily for one year; ${ }^{e}$ Hypertension: $S B P \geq 140 \mathrm{mmHg}$ and/or $\mathrm{DBP} \geq 90 \mathrm{mmHg}$ and/or use of blood pressure medication; fDiabetes: fasting p-glucose $\geq 7.0 \mathrm{mmol} / \mathrm{L}$ and/or HbA1c $\geq 48 \mathrm{mmol} / \mathrm{mol}$ and/or diagnosed (type 1 or type 2). ${ }^{\text {gOne-way ANOVA }}$ (mean and SD). Abbreviations: MICT: moderate-intensity continuous training; HIIT: high-intensity interval training; LDL: lowdensity lipoprotein; HDL: high-density lipoprotein; hSCRP: high-sensitive C-reactive protein; SBP: systolic blood pressure; DBP: diastolic blood pressure; $\mathrm{HbA1c}$ : glycosylated hemoglobin; $\mathrm{VO}_{2 \text { peak: }}$ peak oxygen uptake, a combination of $\mathrm{VO}_{2 \max }$ and $\mathrm{VO}_{2 \text { peak }}$ values; $\mathrm{VO}_{2 \max }$ : maximal oxygen uptake; HADS: Hospital Anxiety and Depression Scale; MoCA: Montreal Cognitive Assessment scores, presented as raw scores.

Table 3. Adherence to the allocated exercise program during the intervention period in the control, moderateintensity continuous training (MICT), and high-intensity interval training (HIIT) groups.

\begin{tabular}{lcccc}
\hline Time & Control & MICT & HIIT & $\boldsymbol{p}_{\text {-value }}$ \\
\hline One-year follow-up & $38 / 42(90.5 \%)$ & $16 / 21(76.2 \%)$ & $23 / 31(74.2 \%)$ & 0.136 \\
Three-year follow-up & $32 / 39(82.1 \%)$ & $15 / 21(71.4 \%)$ & $26 / 30(86.7 \%)$ & 0.379 \\
Five-year follow-up & $33 / 35(94.3 \%)$ & $18 / 21(85.7 \%)$ & $23 / 29(79.3 \%)$ & 0.184 \\
\hline
\end{tabular}

Given as adhering/total number at each timepoint (percentage). ${ }^{a}$ Difference between the groups at each timepoint was tested with Fischer's exact test. Abbreviations: MICT: moderate-intensity continuous training; HIIT: high-intensity interval training. 

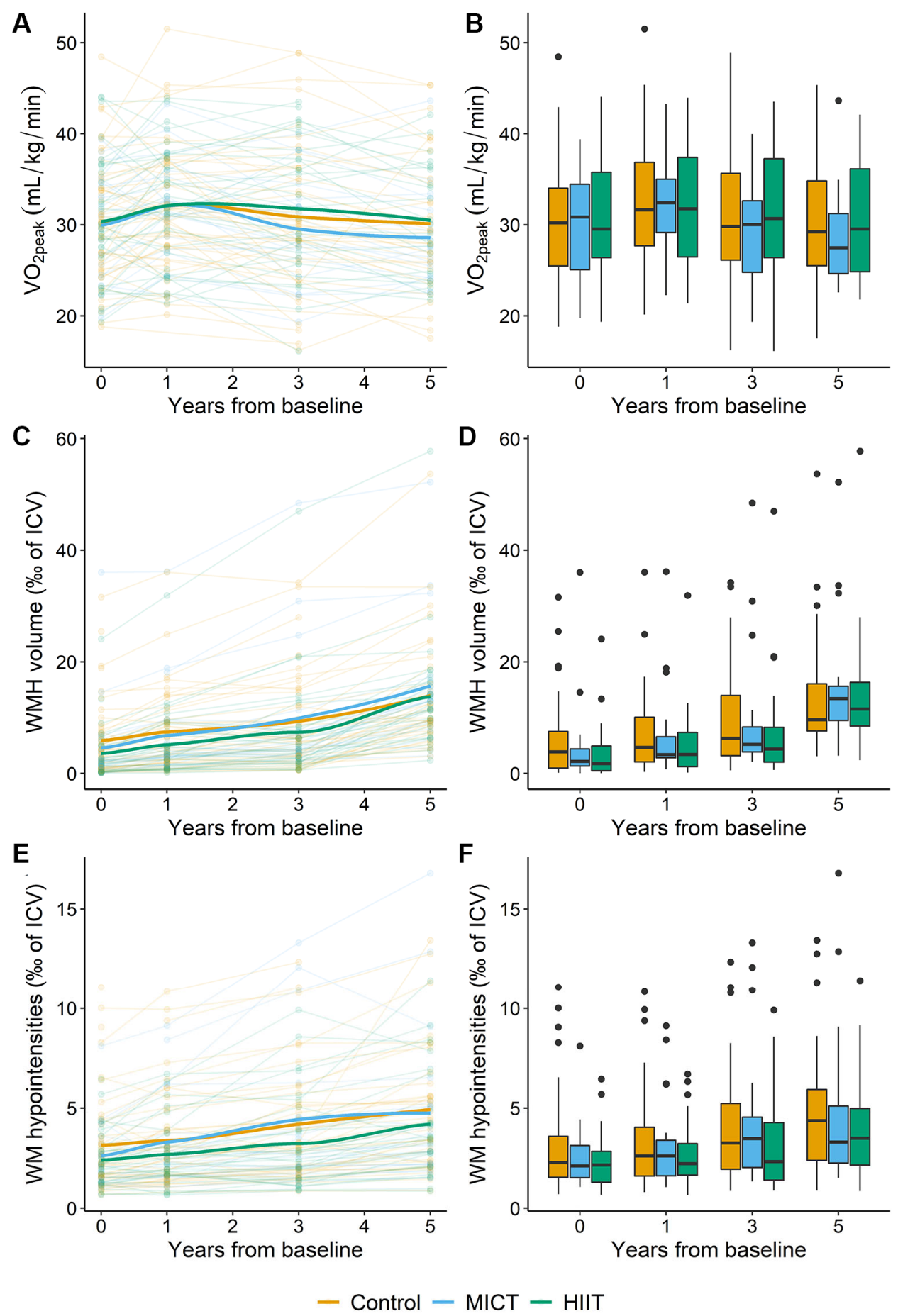

Figure 2. Overview of the development of $\mathrm{VO}_{2 \text { peak, }} \mathrm{WMH}$ and $\mathrm{WM}$-hypointensity volumes (given as \%o of ICV) in the control (orange), MICT (blue) and HIIT (green) groups during the five-year intervention period. (A) Each line represents the $\mathrm{VO}_{2 p e a k}$ values for an individual participant according to group adherence with the thicker lines representing the mean of each group. (B) Box plot of $\mathrm{VO}_{2 \text { peak }}$ in the three intervention groups during the intervention period. (C) Each line represents the WMH volume as \%o of ICV for an individual participant according to group adherence with the thicker lines representing the mean of each group. (D) Box plot of WMH volume as \%o of ICV in the three intervention groups during the intervention. (E) Each line represents the WM-hypointensity volume as \%o of ICV for an individual participant according to group adherence with the thicker lines representing the mean of each group. (F) Box plot of WM-hypointensity volume as \%o of ICV in the three intervention groups during the intervention. In the box plots (B, D, and $\mathbf{F}$ ), the box indicates the interquartile range with the top line of the box representing the third quartile and the bottom line representing the first quartile. The whiskers extend up to the minimum or maximum values, but no further than 1.5 times the interquartile range, and the black dots represent data beyond the end of the whiskers. Abbreviations: $\mathrm{VO}_{2 \text { peak: }}$ peak oxygen uptake; WMH: white matter hyperintensities; ICV: intracranial volume; WM: white matter; MICT: moderate-intensity continuous training; HIIT: high-intensity interval training. 
Table 4. Weekly exercise frequency, duration, and intensity in the control, moderate-intensity continuous training (MICT) and high-intensity interval training (HIIT) group.

\begin{tabular}{|c|c|c|c|c|c|c|}
\hline & \multicolumn{3}{|c|}{ Mean (SD) } & \multicolumn{3}{|c|}{$p$-value } \\
\hline & Control & MICT & HIIT & $\begin{array}{l}\text { Control vs. } \\
\quad \text { MICT }\end{array}$ & $\underset{\text { MICT vs. }}{\text { HIIT }}$ & $\begin{array}{c}\text { Control vs. } \\
\text { HIIT }\end{array}$ \\
\hline \multicolumn{7}{|c|}{ One-year follow-up } \\
\hline Exercise frequency ${ }^{1}$ & $3.0(1.3)$ & $2.8(1.3)$ & $3.3(1.3)$ & NS & NS & NS \\
\hline Exercise duration ${ }^{2}$ & $45.7(14.4)$ & $46.8(8.2)$ & $47.9(9.6)$ & NS & NS & NS \\
\hline Minutes/week exercise & $140.2(77.3)$ & $132.3(75.5)$ & $157.5(70.9)$ & NS & NS & NS \\
\hline Exercise intensity $^{3}$ & $13.8(2.0)$ & $13.6(0.9)$ & $15.2(1.5)$ & 0.267 & $<0.001$ & $<0.001$ \\
\hline \multicolumn{7}{|c|}{ Three-year follow-up } \\
\hline Exercise frequency $^{1}$ & $3.0(1.7)$ & $2.9(1.2)$ & $3.3(1.4)$ & NS & NS & NS \\
\hline Exercise duration ${ }^{2}$ & $46.1(14.0)$ & $49.0(10.0)$ & $47.5(12.2)$ & NS & NS & NS \\
\hline Minutes/week exercise & $146.9(86.7)$ & $147.8(53.8)$ & $155.5(72.5)$ & NS & NS & NS \\
\hline Exercise intensity ${ }^{3}$ & $13.2(2.6)$ & $13.4(0.9)$ & $15.6(1.3)$ & 0.265 & $<0.001$ & $<0.001$ \\
\hline \multicolumn{7}{|c|}{ Five-year follow-up } \\
\hline Exercise frequency $^{1}$ & $3.3(1.6)$ & $2.8(1.3)$ & $3.2(1.4)$ & NS & NS & NS \\
\hline Exercise duration ${ }^{2}$ & $48.4(14.5)$ & $50.1(10.0)$ & $44.4(13.1)$ & NS & NS & NS \\
\hline Minutes/week exercise & $168.3(92.7)$ & $141.1(75.3)$ & $138.5(75.9)$ & NS & NS & NS \\
\hline Exercise intensity ${ }^{3}$ & $13.4(1.7)$ & $12.5(2.1)$ & $15.0(1.4)$ & 0.118 & $<0.001$ & $<0.001$ \\
\hline
\end{tabular}

Difference between the groups at each timepoint was tested with Kruskal-Wallis test and if significant tested with Dunn's test post-hoc. ${ }^{1}$ sessions per week; ${ }^{2}$ minutes per session; ${ }^{3}$ Borg scale, range 6-20. Abbreviations: MICT: moderate-intensity continuous training; HIIT: high-intensity interval training; NS: not significant.

Table 5. Frequency of different types of physical activity in the control, moderate-intensity continuous training (MICT) and high-intensity interval training (HIIT) group at each follow-up during the five-year intervention.

\begin{tabular}{|c|c|c|c|c|c|c|}
\hline & \multicolumn{3}{|c|}{ Mean (SD) } & \multicolumn{3}{|c|}{$p$-value } \\
\hline & Control & MICT & HIIT & $\begin{array}{l}\text { Control vs. } \\
\text { MICT }\end{array}$ & $\begin{array}{c}\text { MICT vs. } \\
\text { HIIT }\end{array}$ & $\begin{array}{c}\text { Control vs. } \\
\text { HIIT }\end{array}$ \\
\hline \multicolumn{7}{|c|}{ One-year follow-up } \\
\hline Walking $^{\mathrm{a}}$ & $2.34(1.20)$ & $2.47(0.95)$ & $2.43(1.72)$ & NS & NS & NS \\
\hline Biking & $0.75(0.93)$ & $1.03(2.18)$ & $1.74(2.09)$ & 0.198 & 0.008 & 0.029 \\
\hline Swimming & $0.27(0.49)$ & $0.21(0.30)$ & $0.51(0.76)$ & NS & NS & NS \\
\hline Skiing ${ }^{\mathrm{b}}$ & $0.71(1.08)$ & $0.71(1.00)$ & $0.73(0.92)$ & NS & NS & NS \\
\hline Fitness center & $0.99(1.19)$ & $0.96(1.18)$ & $1.47(1.36)$ & NS & NS & NS \\
\hline Organized sports & $0.15(0.39)$ & $0.27(0.49)$ & $0.32(0.59)$ & NS & NS & NS \\
\hline Other activities & $0.23(0.66)$ & $0.21(0.39)$ & $0.53(0.82)$ & NS & NS & NS \\
\hline \multicolumn{7}{|c|}{ Three-year follow-up } \\
\hline Walking $^{\mathrm{a}}$ & $2.26(1.26)$ & $1.97(1.36)$ & $2.54(1.73)$ & NS & NS & NS \\
\hline Biking & $0.77(1.16)$ & $1.01(2.01)$ & $1.54(1.91)$ & NS & NS & NS \\
\hline Swimming & $0.28(0.60)$ & $0.09(0.12)$ & $0.53(0.66)$ & 0.097 & 0.004 & $<0.001$ \\
\hline Skiing ${ }^{\mathrm{b}}$ & $0.68(1.10)$ & $0.87(1.70)$ & $0.72(0.97)$ & NS & NS & NS \\
\hline Fitness center & $0.87(1.13)$ & $0.63(0.83)$ & $1.34(1.16)$ & NS & NS & NS \\
\hline Organized sports & $0.30(0.76)$ & $0.27(0.39)$ & $0.59(0.99)$ & NS & NS & NS \\
\hline Other activities & $0.50(0.68)$ & $0.56(0.65)$ & $0.49(0.63)$ & NS & NS & NS \\
\hline \multicolumn{7}{|c|}{ Five-year follow-up } \\
\hline Walking $^{\text {a }}$ & $2.10(1.21)$ & $1.81(1.00)$ & $2.26(1.63)$ & NS & NS & NS \\
\hline Biking & $0.78(1.38)$ & $0.39(0.78)$ & $1.60(2.16)$ & NS & NS & NS \\
\hline
\end{tabular}




\begin{tabular}{|c|c|c|c|c|c|c|}
\hline Swimming & $0.33(0.92)$ & $0.08(0.12)$ & $0.43(0.70)$ & NS & NS & NS \\
\hline Skiing ${ }^{b}$ & $0.56(0.92)$ & $0.21(0.33)$ & $0.49(0.80)$ & NS & NS & NS \\
\hline Fitness center & $0.91(1.30)$ & $0.32(0.64)$ & $1.19(1.13)$ & 0.051 & 0.002 & 0.077 \\
\hline Organized sports & $0.38(1.10)$ & $0.42(0.80)$ & $0.51(0.83)$ & NS & NS & NS \\
\hline Other activities & $0.37(0.52)$ & $0.61(0.62)$ & $0.44(0.40)$ & NS & NS & NS \\
\hline
\end{tabular}

Data are presented as self-reported weekly frequency of listed activities. Difference between the groups at each timepoint was tested with Kruskal-Wallis test and if significant tested with Dunn's test post-hoc. ${ }^{a}$ Walking: as transport, recreational walking, or hiking, ${ }^{b}$ cross-country skiing. Abbreviations: MICT: moderate-intensity continuous training; HIIT: high-intensity interval training; NS: not significant.

Table 6. Total (A) and relative to ICV (B) WMH, PWMH, DWMH and WM-hypointensity volumes at each timepoint for all participants, given as median and interquartile range.

\begin{tabular}{|c|c|c|c|c|}
\hline Time & WMH & PWMH & DWMH & WM-hypointensity \\
\hline \multicolumn{5}{|c|}{ (A) Total volume $\left(\mathrm{cm}^{3}\right)$} \\
\hline Baseline & $4.1(8.4)$ & $3.3(6.5)$ & $0.6(2.3)$ & $3.5(3.2)$ \\
\hline One-year follow-up & $5.7(12.1)$ & $4.7(8.0)$ & $0.9(2.7)$ & $4.0(3.3)$ \\
\hline Three-year follow-up & $8.8(14.6)$ & $7.1(11.3)$ & $1.3(2.8)$ & $5.0(5.5)$ \\
\hline Five-year follow-up & $19.2(14.2)$ & $15.7(12.7)$ & $3.0(3.6)$ & $6.1(6.0)$ \\
\hline \multicolumn{5}{|c|}{ (B) Volume relative to ICV (\%o of ICV) } \\
\hline Baseline & $2.5(5.4)$ & $2.2(3.9)$ & $0.4(1.4)$ & $2.2(2.0)$ \\
\hline One-year follow-up & $3.5(7.6)$ & $3.1(5.1)$ & $0.6(1.6)$ & $2.5(2.2)$ \\
\hline Three-year follow-up & $5.6(8.7)$ & $4.4(5.9)$ & $0.7(1.6)$ & $3.0(3.3)$ \\
\hline Five-year follow-up & $11.9(7.8)$ & $10.3(7.1)$ & $1.8(2.0)$ & $3.5(3.4)$ \\
\hline
\end{tabular}

In (B) the WMH, PWMH, DWMH and WM-hypointensity volumes were divided by ICV and multiplied by 1000, i.e., reported as $\%$ of ICV. Abbreviations: WMH: white matter hyperintensities; PWMH: periventricular WMH; DWMH: deep WMH; WM: white matter; IQR: interquartile range.

Table 7. The effect of the five-year intervention on WMH, PWMH, DWMH and WM-hypointensity volumes in the MICT and HIIT groups compared to the control group.

\begin{tabular}{lcccccccccccc}
\hline \multirow{2}{*}{ Predictors } & \multicolumn{4}{c}{ WMH } & \multicolumn{3}{c}{ PWMH } & \multicolumn{3}{c}{ DWMH } & \multicolumn{3}{c}{ WM-hypointensity } \\
\cline { 2 - 12 } & Est. & $\mathbf{C I}(\mathbf{9 5} \%)$ & $\boldsymbol{p}$-value & Est. & $\mathbf{C I} \mathbf{( 9 5 \% )}$ & $\boldsymbol{p}$-value & Est. & $\mathbf{C I} \mathbf{( 9 5 \% )}$ & $\boldsymbol{p}$-value & Est. & CI (95\%) & $\boldsymbol{p}$-value \\
\hline Women & 1.95 & $-1.29,5.19$ & 0.235 & 0.83 & $-1.13,2.79$ & 0.404 & 1.14 & $-0.35,2.62$ & 0.131 & -0.80 & $-1.83,0.22$ & 0.124 \\
Age & 0.28 & $-0.56,1.12$ & 0.507 & 0.48 & $-0.03,0.98$ & 0.067 & -0.14 & $-0.51,0.23$ & 0.447 & 0.33 & $0.06,0.60$ & $\mathbf{0 . 0 1 6}$ \\
1-Year & 1.03 & $-0.71,2.77$ & 0.245 & 0.47 & $-0.69,1.64$ & 0.424 & 0.81 & $0.16,1.46$ & $\mathbf{0 . 0 1 5}$ & -0.03 & $-0.62,0.56$ & 0.921 \\
3-Year & 2.35 & $-0.58,5.27$ & 0.115 & 1.17 & $-0.67,3.01$ & 0.212 & 1.22 & $0.01,2.44$ & $\mathbf{0 . 0 4 9}$ & 0.09 & $-0.87,1.04$ & 0.856 \\
5-Year & 7.58 & $3.00,12.16$ & $\mathbf{0 . 0 0 1}$ & 4.50 & $1.67,7.33$ & $\mathbf{0 . 0 0 2}$ & 2.62 & $0.65,4.59$ & $\mathbf{0 . 0 0 9}$ & 0.53 & $-0.94,2.00$ & 0.477 \\
MICT & -0.89 & $-5.19,3.42$ & 0.683 & -0.59 & $-3.24,2.05$ & 0.659 & -0.24 & $-2.16,1.69$ & 0.808 & -0.23 & $-1.61,1.15$ & 0.739 \\
HIIT & -2.11 & $-6.02,1.81$ & 0.288 & -1.54 & $-3.94,0.86$ & 0.205 & -0.30 & $-2.05,1.45$ & 0.733 & -0.72 & $-1.97,0.53$ & 0.258 \\
MICT*1-year & -0.41 & $-2.66,1.83$ & 0.718 & -0.18 & $-1.76,1.41$ & 0.828 & -0.31 & $-0.98,0.36$ & 0.368 & -0.31 & $-1.12,0.51$ & 0.457 \\
MICT*3-year & 0.77 & $-1.55,3.09$ & 0.515 & 0.61 & $-1.03,2.24$ & 0.466 & 0.05 & $-0.65,0.74$ & 0.899 & 0.12 & $-0.71,0.95$ & 0.770 \\
MICT*5-year & 0.97 & $-1.34,3.28$ & 0.408 & 1.20 & $-0.43,2.83$ & 0.147 & 0.10 & $-0.60,0.79$ & 0.783 & -0.57 & $-1.39,0.25$ & 0.174 \\
HIIT*1-year & 0.42 & $-1.58,2.43$ & 0.679 & 0.20 & $-1.21,1.61$ & 0.277 & -0.21 & $-0.81,0.39$ & 0.498 & -0.03 & $-0.74,0.69$ & 0.942 \\
HIIT*3-year & 0.71 & $-1.33,2.76$ & 0.493 & 0.52 & $-0.92,1.95$ & 0.480 & -0.11 & $-0.73,0.50$ & 0.719 & -0.16 & $-0.89,0.56$ & 0.658 \\
HIIT*5-year & 1.38 & $-0.71,3.47$ & 0.193 & 1.46 & $-0.00,2.92$ & 0.050 & -0.25 & $-0.88,0.38$ & 0.439 & -0.37 & $-1.10,0.37$ & 0.326 \\
\hline AIC & & & 2095.1 & & & 1812.4 & & & 1330.1 &
\end{tabular}

WMH, PWMH, DWMH, WM-Hypointensity volumes were corrected for ICV and multiplied by 1000 (\%o of ICV). All analyses were adjusted for age, sex, and baseline outcome values. The control group was the reference group. There were no interactions between sex, age, time (year one, three and five) or the training interventions (MICT and HIIT) and these terms were therefore removed from the statistical models. Abbreviations: WMH: white matter hyperintensities; PWMH: periventricular WMH; DWMH: deep WMH; WM: white matter; Est.: estimates; Cl: confidence interval; $\mathrm{MICT}$ : moderate-intensity continuous training; HIIT: high-intensity interval training; AIC: Akaike's information criterion. 
Table 8. A longitudinal linear mixed model of WMH, PWMH, DWMH and WM-hypointensity volumes with $\mathrm{VO}_{2 \text { peak }}$ at time of each follow up as a predictor across all participants.

\begin{tabular}{|c|c|c|c|c|c|c|c|c|c|c|c|c|}
\hline \multirow{2}{*}{ Predictors } & \multicolumn{3}{|c|}{ WMH } & \multicolumn{3}{|c|}{ PWMH } & \multicolumn{3}{|c|}{ DWMH } & \multicolumn{3}{|c|}{ WM-hypointensity } \\
\hline & Est. & CI $(95 \%)$ & $p$-value & Est. & CI $(95 \%)$ & $p$-value & Est. & CI $(95 \%)$ & $p$-value & Est. & CI $(95 \%)$ & $p$-value \\
\hline Women & 2.21 & $-1.04,5.45$ & 0.181 & 0.98 & $-0.99,2.96$ & 0.327 & 1.23 & $-0.32,2.78$ & 0.118 & -0.93 & $-1.96,0.10$ & 0.076 \\
\hline Age & 0.27 & $-0.56,1.10$ & 0.518 & 0.47 & $-0.04,0.97$ & 0.071 & -0.18 & $-0.57,0.21$ & 0.369 & 0.30 & $0.04,0.57$ & 0.025 \\
\hline Year one & 1.03 & $-0.47,2.52$ & 0.176 & 0.49 & $-0.47,1.45$ & 0.313 & 0.77 & $0.10,1.44$ & 0.024 & -0.03 & $-0.53,0.47$ & 0.919 \\
\hline Year three & 2.72 & $-0.04,5.48$ & 0.053 & 1.49 & $-0.23,3.20$ & 0.088 & 1.37 & $0.08,2.65$ & 0.038 & 0.23 & $-0.67,1.12$ & 0.617 \\
\hline Year five & 8.39 & $3.96,12.81$ & $<0.001$ & 5.40 & $2.68,8.11$ & $<0.001$ & 3.05 & $0.97,5.13$ & 0.004 & 0.47 & $-0.94,1.89$ & 0.509 \\
\hline $\mathrm{VO}_{2 \text { peak }}$ & -0.00 & $-0.12,0.12$ & 0.998 & -0.01 & $-0.09,0.07$ & 0.778 & -0.00 & $-0.05,0.05$ & 0.900 & -0.03 & $-0.07,0.01$ & 0.153 \\
\hline AIC & & & 1986.4 & & & 1713.3 & & & 1422.7 & & & 1314.5 \\
\hline
\end{tabular}

WMH, PWMH, DWMH, WM-hypointensity volumes were corrected for ICV and multiplied by 1000 (\%o of ICV). All analyses were adjusted for age, sex, and baseline outcome values. The control group was the reference group. There were no interactions between sex, age, time (year one, three and five) or $\mathrm{O}_{2 \text { peak }}$ and these terms were therefore removed from the statistical models. Abbreviations: $\mathrm{WMH}$ : white matter hyperintensities; $\mathrm{PWMH}$ : periventricular WMH;

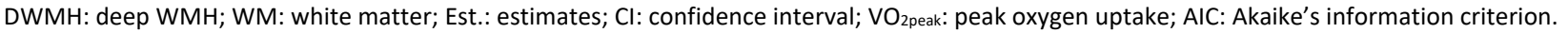

Table 9. Linear mixed 'model of changes' analyses with yearly change in $\mathrm{VO}_{2 \text { peak }}\left(\Delta \mathrm{VO}_{2 \text { peak }}\right)$ as predictor of yearly change in WMH, PWMH, DWMH, and WM-hypointensity volumes across all participants.

\begin{tabular}{lcccccccccccc}
\hline \multirow{2}{*}{ Predictors } & \multicolumn{3}{c}{ WMH change } & \multicolumn{3}{c}{ PWMH change } & \multicolumn{3}{c}{ DWMH change } & \multicolumn{2}{c}{ WM-hypointensity change } \\
\cline { 2 - 12 } & Est. & CI (95\%) & $\boldsymbol{p}$-value & Est. & CI (95\%) & $\boldsymbol{p}$-value & Est. & CI (95\%) & $\boldsymbol{p}$-value & Est. & CI (95\%) & $\boldsymbol{p}$-value \\
\hline Women & 0.28 & $-0.34,0.90$ & 0.380 & 0.17 & $-0.23,0.58$ & 0.400 & 0.26 & $0.03,0.50$ & $\mathbf{0 . 0 2 9}$ & -0.09 & $-0.29,0.11$ & 0.363 \\
Age $^{\mathrm{a}}$ & 0.18 & $0.04,0.32$ & $\mathbf{0 . 0 1 4}$ & 0.16 & $0.07,0.26$ & $\mathbf{0 . 0 0 1}$ & -0.02 & $-0.07,0.03$ & 0.396 & 0.03 & $-0.01,0.08$ & 0.136 \\
$\Delta \mathrm{VO}_{2 \text { peak }}$ & 0.09 & $-0.01,0.19$ & 0.088 & 0.04 & $-0.03,0.11$ & 0.266 & 0.02 & $-0.02,0.05$ & 0.291 & 0.01 & $-0.02,0.04$ & 0.484 \\
\hline $\mathrm{AIC}$ & & & 985.2 & & & 800.4 & & & 531.0 & & 476.6 \\
\hline
\end{tabular}

WMH, PWMH, DWMH, WM-hypointensity volumes were corrected for ICV and multiplied by 1000 (\%o of ICV). Yearly changes were calculated from inclusion to one-year, one-year to three-year, and three-year to five-year of the intervention. There were no interactions between sex, age, or $\mathrm{VO}_{2 \text { peak }}$ and these terms were therefore removed from the statistical models. ${ }^{a}$ The participants' mean age at each time interval. ${ }^{2}$ Yearly change in peak oxygen uptake of the three follow up intervals. Abbreviations: $\mathrm{WMH}$ : white matter hyperintensities; $\mathrm{PWMH}$ : periventricular $\mathrm{WMH}$; DWMH: deep WMH; WM: white matter; Est.: estimates; $\mathrm{Cl}$ : confidence interval; $\mathrm{VO}_{2 \text { peak: }}$ peak oxygen uptake.

were uncovered for PWMH volume. However, DWMH volume was significantly positively associated with time at year one, three and five. WM-hypointensity volume was not associated with group, group*time or time, but there was a significant effect of age.

The analysis assessing the difference between the combined supervised exercise group (MICT\&HIIT) versus control found a significant interaction between group and time at year five for the PWMH volume (Supplementary Table 1), with participants in the supervised exercise group having larger PWMH volume with time (Supplementary Figure 1). The results were similar in the supplemental analyses, which included WMH risk factors: current smoking, hypertension, BMI and HADS score as predictive variables in the same models as above (results not shown).

Across the three groups, no significant associations between $\mathrm{VO}_{2 \text { peak }}$ and $\mathrm{WMH}$ volume were found at any of the follow-ups (Table 8). Similar results were present for PWMH, DWMH and WM-hypointensity volumes. The results did not change when including current smoking, hypertension, BMI and HADS score as predictive variables in the supplemental analyses with $\mathrm{WMH}$, PWMH, DWMH or WM-hypointensity volume as outcomes (results not shown).

Across all participants, the 'model of changes' demonstrated no effect of change in $\mathrm{VO}_{2 \text { peak }}$ on change in WMH, PWMH, DWMH, or WMhypointensity volume (Table 9). There was a significant effect of age; the older a participant was, the greater the increase in WMH and PWMH volume. Being a woman was associated with a greater increase in DWMH volume.

Baseline $\mathrm{VO}_{2 \text { peak }}$ did not predict $\mathrm{WMH}$ change over five years $(p=0.754)$.

\section{DISCUSSION}

In this MRI sub-study of participants from the RCT Generation 100 Study, we did not find evidence of five years of supervised MICT or HIIT intervention attenuating the development of WMH compared to the control group following the national physical activity guidelines. Neither did we uncover a positive 
association between cardiorespiratory fitness $\left(\mathrm{VO}_{2 \text { peak }}\right)$ and $\mathrm{WMH}$, nor change in $\mathrm{VO}_{2 \text { peak }}$ on change in $\mathrm{WMH}$ volume at any timepoint during the intervention. Likewise, no intervention or $\mathrm{VO}_{2 \text { peak }}$ effect on $\mathrm{PWMH}, \mathrm{DWMH}$ and WM-hypointensity volumes were present. Including known risk factors for $\mathrm{WMH}$ as predictors in the statistical models did not alter these results. The lack of a group difference in $\mathrm{WMH}$ volume was present even though all three groups adhered well to their respective training regimes, with the HIIT group training at a higher intensity and partaking in different types of activities than the MICT and control groups. However, in the combined supervised exercise group, a significant interaction between time and group was uncovered, with the intervention group experiencing greater PWMH volume growth after five years. Taken together, supervised exercise was not found to be beneficial above following national physical activity guidelines, and level of cardiorespiratory fitness was not found to attenuate the growth of the investigated WMH measures contrary to our predictions.

Our results were in line with the recent two-year AIBL active intervention study with subject-specific selfadministered physical activity of medium intensity versus usual care/lifestyle advice in older communitydwelling adults of similar age as in our study [24]. In that study, no positive effect of the intervention was uncovered for manually derived longitudinal $\mathrm{WMH}$ volume from 3D FLAIR scans acquired at 3T [24]. A possible explanation for the lack of a group effect in both the AIBL active and our study could be similarities in fitness levels between the intervention and control groups. In Venkatraman et al. [24], fitness/motor test scores were similar in both groups, while in our study, the groups had similar $\mathrm{VO}_{2 \text { peak }}$ during the intervention. No effect on WMH development has also been reported in the PROMOTE study with thrice weekly aerobic exercise versus usual care in adults aged 55 years and older with MCI [22] and in the multidomain intervention versus usual care, FINGER study, in an at-risk population [23]. Since physical activity was only one of several approaches implemented in the FINGER study, it is not directly comparable to our study. Still, the FINGER study reported a positive effect of their multidomain intervention on processing speed in the participants with the largest structural brain reserve [29]. In our study cohort, processing speed was positively associated with $\mathrm{VO}_{2 \text { peak }}$ across all participants, and increasing $\mathrm{VO}_{2 \text { peak }}$ during the intervention improved working memory [30]. Taken together, this might suggest that interventions including exercise and/or physical activity provide brain functional benefits even if brain structural benefits cannot be detected.
In contrast to the intervention studies, which did not report intervention effects on $\mathrm{WMH}$, two three-year observational studies on the effect of physical activity on $\mathrm{WMH}$ volumes showed a positive association between level of physical activity on WMH volume over time, but only when comparing the most and the least physically active, cognitively unimpaired participants [26, 31]. In these studies, the most physically active groups with significantly lower WMH volume at the end of the intervention exercised at $>1200$ metabolic equivalent of task (MET)-minutes/week and $>1875 \mathrm{kcal}$ per week, respectively. Most participants in our study did not exercise at this level. Moreover, the reference groups in the aforementioned studies spent $<600 \mathrm{MET}-\mathrm{min} /$ week and $<217 \mathrm{kcal}$ and on physical activity, respectively. This is lower than the physical activity levels of our control group. This could imply that very vigorous and frequent physical activity is required to attenuate $\mathrm{WMH}$ volume over time.

In the combined exercise group, a significant group*time effect was uncovered at five years, but contrary to our prediction, PWMH growth was greatest in the intervention group. Figure 2 depicting overall WMH volume over time suggests a greater $\mathrm{WMH}$ growth in MICT and HIIT compared to controls over time, but a clear change in trajectory was only observed in the combined MICT\&HIIT group (Supplementary Figure 1). The periventricular region is supplied by short, penetrating high flow vessels sensitive to hypertension and is linked to stroke risk [9, 32, 33]. Furthermore, PWMH volumes correlate with several genes connected to vascular function and vascular diseases in the brain and heart [8]. Since exercise improves vascular function and prevents cardiovascular disease [34-36], a specific adverse effect of the intervention on $\mathrm{PWMH}$ volume over time was unexpected. However, we have previously shown a time* group interaction for hippocampal volume in the same cohort with the HIIT and combined HIIT and MICT groups experiencing faster hippocampal atrophy rate from year three [37]. Such negative effects on brain structure could relate to the older brain being more sensitive or more likely to experience hypoperfusion during intense exercising [25].

The similar $\mathrm{VO}_{2 \text { peak }}$ level in the three groups across the intervention period was unexpected given that the groups exercised according to their assigned regime throughout the five-year period. HIIT is anticipated to increase $\mathrm{VO}_{2 \text { peak }}$ the most [38], and a small but significantly higher $\mathrm{VO}_{2 \text { peak }}$ was present in HIIT compared to MICT and control groups in the full RCT Generation 100 Study sample [27]. In the MRI substudy, the participants had a significantly higher $\mathrm{VO}_{2 \text { peak }}$ at baseline than the rest of the RCT Generation 
100 participants, which might have contributed to the lack of a group difference, even if the HIIT group in the MRI sample consistently exercised at a higher intensity level that the MICT and control groups. Furthermore, $\mathrm{VO}_{2 \text { peak }}$ at baseline did not predict change in WMH volume over five years. This was at odds with findings for cortical volumes in the same cohort, where $\mathrm{VO}_{2 \text { peak }}$ at baseline was positively associated with cortical volume at five years [37]. Different brain tissues may hence be differentially sensitive to the effect of exercising and cardiorespiratory fitness levels. Since the mean $\mathrm{VO}_{2 \text { peak }}$ level in our sample was similar to that in people of the same age in a large Norwegian general population study [39], our results should be generalizable to older cognitively intact communitydwelling adults. The absence of an association between
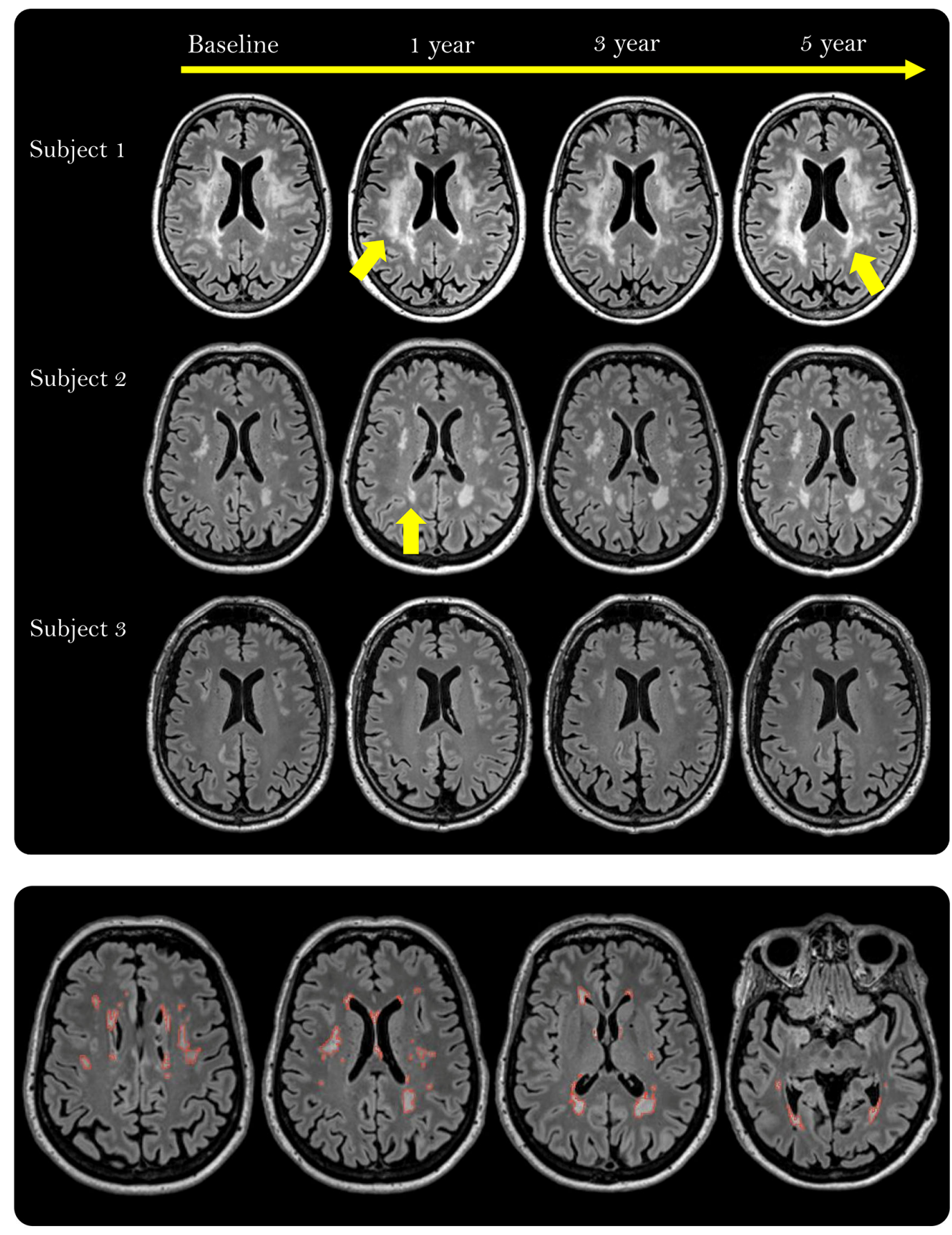

Figure 3. White matter hyperintensities (WMHs) depicted as white, well-defined lesions or confluent areas in white matter on fluid-attenuated inversion recovery (FLAIR) scans in three participants during the 5-year intervention period. The yellow arrows point to areas with growing WMH lesions (Subject 1) or a new lesion (Subject 2). The lower row shows the manually delineated WMHs (red outline) across 4 out of 176 slices in one participant. 
$\mathrm{VO}_{2 \text { peak }}$ and $\mathrm{WMH}$ volume and change in $\mathrm{VO}_{2 \text { peak }}$ and change in $\mathrm{WMH}$ volume at any timepoint during the intervention makes it unlikely that $\mathrm{VO}_{2 \text { peak }}$ by itself is a central mechanism in preventing WMH. Since nonexercise/physical activity intervention studies in adults between 40-90 years of age find significantly reduced growth of WMH following pharmacological (e.g., antihypertensives, intranasal insulin), life-style (e.g., diabetes mellitus type 2), and physiological (e.g., preconditioning) interventions [40-43], it might be that aerobic exercise intervention alone is less effective at reducing WMH compared to targeting other or several mechanisms associated with WMH.

The WMH and WM-hypointensity volumes in the participants at baseline were highly similar to findings of older adults within the same age range using the same type of scans and WMH delineation methods [44, 45], as well as in published longitudinal studies on physical activity and exercise $[24,26]$. Moreover, the Generation 100 participants had the expected increase in $\mathrm{WMH}$ volume with time. However, the rate of $\mathrm{WMH}$ volume growth in our sample was in the higher end of previously published data [46-48]. It is to be mentioned that both cross-sectional volume and longitudinal WMH volumes vary substantially between publications, probably due to the many different methodologies used for WMH measurements [26, 47-50]. In our study, only DWMH volume increased at each follow-up, while total WMH and PWMH volumes were significantly increased only at five years. The faster growth of DWMH could be due to the greater area available for growth. Presence and growth of WMH are associated with health factors such as hypertension, weight, and mental health, which affect white matter long before WMH become visible [51, 52]. Many of these factors interact with physical activity over time, representing time-dependent confounders, which makes it difficult to unravel the relationships between the different mechanisms involved in WMH formation [53]. After 70 years of age, it might be that changes in white matter related to lifelong exposure to physiological, health and environmental factors have come too far to be altered by an exercise intervention. Other effects of physical activity and aerobic exercising than improved $\mathrm{VO}_{2}$, such as better cardiovascular health, body weight control, and exercise-induced increases in levels of substances in blood (e.g., BDNF, lactate), have been suggested as important, beneficial mechanisms of exercise on the brain [54]. Since there were no differences in the demographic and clinical characteristics between the three groups in our study at any timepoint during the intervention, and adding WMH risk factors to the models did not alter the results (supplemental analyses), it seems unlikely that differences in clinical health related to MICT, HIIT or physical activity according to national guidelines could have affected our results.

Women had a greater DWMH volume increase across the five-year intervention compared to men in our study. Previous studies have reported sex differences in PWMH volume [13] and total WMH volume, but with a low explanatory power [55]. Our results imply that growth in WMH volume is more related to sex than cross-sectional WMH volume per se in the $70+$ age group. Given that DWMH are a risk factor of dementia [12] which women are at an increased risk of [56], this finding has potential clinical relevance.

WM-hypointensity volume was, like WMH volume, not associated with group or group*time interaction. The WM-hypointensity measure shares characteristics with automated segmentation algorithms for $\mathrm{WMH}$ obtained from T2-weighted/FLAIR scans in that both report smaller WMH volumes mainly located in deep white matter and are limited to voxels with markedly higher (T2-weighted) or lower (T1-weighted) signal intensity, considered to reflect more severely affected white matter. Our results suggested that supervised HIIT and MICT exercising were not effective in preventing the growth of this type of age-related WM change either. Most observation and intervention studies examining relationships between physical activity and WMH have used (semi-)automated WMH segmentation methods, and most of these report positive results [26, 49, 57-59]. We were not able to find a similar positive relationship with WM-hypointensity volume. The consistent findings with manually and automatically derived WMH volumes on this study demonstrated that differences in WMH segmentation methods cannot explain our null results.

\section{Strengths and limitations}

The strengths of this study included the general population-based sample, the limited age range, even distribution between men and women, prospective, RCT design, long intervention period, clinical measures, ergospirometry $\mathrm{VO}_{2}$ assessments, detailed physical activity data and brain MRI at baseline, one-, three- and five years. MRI was obtained on the same scanner with the same coil and the same scan protocol at all timepoints. The WMH volumes were obtained by manual delineation, considered the gold standard of WMH quantification [44, 60], as well as with an automated method, and these methods were significantly associated. The scans for WMH delineation were 3D FLAIR scans, which are considered to allow for the highest reliability and reproducibility of $\mathrm{WMH}$ volume measurements, and deemed the most sensitive method to uncover a change 
in WMH volume over time [61-63]. The two raters performed highly consistent and similar measurements. All data were missing at random. Correction for baseline values was implemented as recommended by Twisk [64]. The sample size was determined based on publications available at time of the application to the ethical committee and should be able to uncover group differences. Nevertheless, only the analysis with the combined supervised exercise group revealed a significant time* group interaction, although not in the expected direction. An increase in power by combining the MICT and HIIT groups (higher $\mathrm{n}$ and two groups) was likely the reason for this since the estimates from the mixed linear model analyses for PWMH volumes in the MICT and HIIT versus the control group (Table 7) and the combined MICT\&HIIT group versus the control group (Supplementary Table 1) were quite similar. We added the table with WMH volumes at each timepoint to guide future power analysis in this research area, as the cross-sectional and longitudinal studies published since this study started report varying results $[19,20$, $22,23,26,40,47-50,58,59,65-68]$.

Our participants were on average quite healthy with fewer current smokers and less diabetes and hypertension than in average 67-79 years old Norwegians $[69,70]$. The participants in the MRI study of the Generation 100 study were also more educated, had a higher mean $\mathrm{VO}_{2 \text { peak }}$ level and lower blood fat level than those not volunteering for the MRI sub-study. Inclusion of a control group might have precluded uncovering an effect of the supervised exercise intervention, but it was considered unethical not to have the control group follow the national guidelines on physical activity based on the current evidence regarding somatic health and mortality. Many previous studies examining WMH and physical activity/exercise have included at-risk populations or hospital samples $[22,23,26,31,40,71]$. Since $\mathrm{WMH}$ is common in older adults [1], it is also important to investigate this phenomenon in the general population, including healthy older adults, to devise inclusive strategies for optimal brain aging.

\section{CONCLUSION}

This is the first five-year intervention study implementing exercise interventions at two intensities and a control group, recruited from the general population of community-dwelling older adults born between 1936 and 1942. The exercise intervention did not influence WMH, PWMH, DWMH, or WMhypointensity volume growth compared to the control group following national recommendations for physical activity. Neither was $\mathrm{VO}_{\text {2peak }}$ at any timepoint nor change in $\mathrm{VO}_{2 \text { peak }}$ associated with any $\mathrm{WMH}$ measurement in any group, and baseline $\mathrm{VO}_{2 \text { peak }}$ did not predict WMH growth. Exercise in old age has several benefits and should be recommended to improve overall health but taking part in MICT or HIIT does not protect against WMH progression compared to following national physical activity guidelines.

\section{MATERIALS AND METHODS}

\section{Ethics}

The project was approved by the Regional Committee for Medical Research Ethics, Central Norway $(2012 / 849)$ and adhered to the Declaration of Helsinki. All participants signed an informed written consent before inclusion.

\section{Study population}

The participants were from the RCT Generation 100 Study

(NCT01666340, http://clinicaltrials.gov/ct2/show/NCT01666340)

approved separately by the Regional Committee for Medical Research Ethics, Central Norway (2012/381 B) [28]. The RCT assessed the effect of five years of twice weekly supervised MICT or HIIT compared to the national recommendations of at least 30 minutes moderate-intensity physical activity almost every day [72] on all-cause mortality in older adults [27].

In 2012, invitation letters were sent to 6966 adults (3 721 women) born between 1936-1942 and registered in the Norwegian National Population Registry with a permanent home address in Trondheim municipality. Of these, 1790 showed an interest, and 1567 (790 women) passed the inclusion criteria while 223 were excluded. Exclusion criteria were any condition or disease precluding partaking in an exercise intervention and diagnosed dementia as well as participation in other exercise intervention studies [28]. The participants were informed of the possibility of also taking part in a neuroimaging investigation during the baseline data collection in the Generation 100 RCT. Exclusion criteria for the MRI study were limited to standard MRI contraindications (e.g., implanted electronic medical devices) and brain pathology, which would interfere with image analysis.

After inclusion, the Unit for Applied Clinical Research, NTNU, used a web-based approach to randomize the participants 2:1:1, stratified by sex and cohabitation status (living with someone versus alone) into following the national physical activity guidelines (i.e., $>30$ minutes of moderate-intensity physical activity almost every day) (control group, $n=780$ ), or supervised exercise with either MICT $(n=387)$ or HIIT $(n=400)$ 
[28]. The supervised MICT sessions consisted of 50 minutes of continuous workout or exercise at about $70 \%$ of peak heart rate corresponding to a rating of perceived exertion of approximately 13 on the Borg scale [73]. The supervised HIIT sessions included 10-minute warm-up followed by $4 \times 4$ minute intervals between $85-95 \%$ peak heart rate corresponding to a rating of perceived exertion of approximately 16 on the Borg scale. Between the intervals, there were three-minute active breaks. Participants could perform their training sessions individually at their assigned intensity level after instruction. Every sixth week, the MICT and HIIT groups attended mandatory spinning classes where they exercised with a heart rate monitor to ascertain compliance with the prescribed training intensity. Of those included in the Generation 100 Study, 108 participants were interested in undergoing neuroimaging. Of these, two were excluded due to MRI contraindications, and one was excluded due to preexisting brain pathology leaving 105 participants to be included.

Sample size for the neuroimaging project was calculated at the time of the application to the ethical committee based on previously WMH volume growth which varied greatly [50, 74], giving group sizes ranging from 4 to 52 individuals to uncover significant group differences.

Baseline MRI acquisition started in August 2012 and lasted till June 2013. Follow-ups were performed one, three, and five years after baseline data collection, with five-year MRI scans collected between August 2017 and June 2018.

For the MICT and HIIT groups, adherence to the prescribed intervention was based on reported frequency, duration, and intensity of exercise. This information was obtained from the physical activity questionnaires at the one-, three- and five-year followups [28]. As per the RCT protocol, adherence to the assigned program was met if the participant fulfilled at least $50 \%$ of the prescribed sessions [28]. For HIIT, adherence was defined as exercising at least $\geq 30$ minutes $\geq 15$ on the Borg scale per week, and for MICT at least $\geq 30$ minutes at $11-14$ on the Borg scale per week. For the controls, adherence was based on performing at least $\geq 75$ minutes of physical activity (i.e., including all intensities, Borg 6-20) per week. Adherence for each group was calculated as the number of participants adhering to the prescribed exercise/physical activity divided by the total number of participants in the group at that timepoint and presented as a percentage. From the same questionnaire, exercise frequency per week, exercise duration in minutes per session, and intensity rated with the Borg scale were derived for each participant at the follow ups. Finally, the frequency of performing different types of activities was assessed from the following questions: "How often do you do the following: 1. Walk: a) as a way of transportation, b) recreational walking, c) hiking in nature); 2. Bike; 3. Swim; 4. Ski; 5. Train at a fitness center; 6. Participate in organized sports; 7. Participate in other physical activities". The response options were: "Never" scored as 0 ; "Rarely" scored as 0.25 ; " $1-3$ times a month" scored as 0.5 ; "once a week" scored as 1 , "2-3 times a week" scored as 2.5 ; " $4-6$ times a week" scored as 5; and "Daily" scored as 7. The weekly frequencies of the different activities were used to compare the different groups.

\section{Demographic, clinical data and cardiorespiratory fitness measurement}

All participants completed a questionnaire concerning their demographical information and health. Education was stratified into primary school, high school/ vocational school, and higher education. Smoking was registered as 'current smoker' (yes/no) at all timepoints and as pack-years at baseline, i.e., the number of packs of cigarettes smoked per day multiplied by the number of years the person smoked.

Clinical measurements were obtained at baseline and one, three, and five years after inclusion. Height, weight, waist circumference, and blood pressure (BP), were measured using best clinical practices [28]. Fasting blood was drawn and analyzed for serum triglycerides (TG), glucose, low-density lipoprotein (LDL), high-density lipoprotein (HDL), total cholesterol, glycosylated hemoglobin ( $\mathrm{HbA} 1 \mathrm{c})$, and high-sensitive CRP (hsCRP). A diagnosis of diabetes (type 1 and type 2) was based on reporting a diagnosis of diabetes, and/or fasting blood glucose $\geq 7.0$ $\mathrm{mmol} / \mathrm{L}$, and/or HbAlc $\geq 48 \mathrm{mmol} / \mathrm{mol}$ [75]. Hypertension was defined as reporting a hypertension diagnosis, and/or use of antihypertensives, and/or systolic $\mathrm{BP} \geq 140 \mathrm{mmHg}$ and/or diastolic $\mathrm{BP} \geq 90$ $\mathrm{mmHg}$ [76]. The validated Norwegian version of the Hospital Anxiety and Depression Scale (HADS) was used to assess anxiety and depression levels, with higher scores indicating increased symptom burden (range 0-42) [77, 78]. At the 5-year assessment, the Norwegian validated Montreal Cognitive Assessment (MoCA) tool was used to evaluate cognition [79]. The score range is 0 to 30 , where a lower score denotes lower cognitive ability. The raw scores are presented and the cut offs for a diagnosis of mild cognitive impairment (MCI) is a score of 21 for primary, 22 for secondary, and 24 for high educational attainment for the age group 75-85 years based on Scandinavian norms [80]. 
Table 10. MRI scan parameters for scans acquired at 3T used in this study.

\begin{tabular}{lccc}
\hline Parameter & 3D T1 & 3D T2 & 3D T2 FLAIR \\
\hline Orientation & Sagittal & Sagittal & Sagittal \\
TR & $1900 \mathrm{~ms}$ & $3200 \mathrm{~ms}$ & $5000 \mathrm{~ms}$ \\
TE & $3.16 \mathrm{~ms}$ & $412 \mathrm{~ms}$ & $388 \mathrm{~ms}$ \\
TI & $900 \mathrm{~ms}$ & $\mathrm{n} / \mathrm{a}$ & $1650 \mathrm{~ms}$ \\
No. of Slices & 192 & 176 & 176 \\
Slice Thickness & $1.0 \mathrm{~mm}$ & $1.0 \mathrm{~mm}$ & $1.0 \mathrm{~mm}$ \\
FOV & $256 \times 256 \mathrm{~mm}$ & $250 \times 250 \mathrm{~mm}$ & $256 \times 256 \mathrm{~mm}$ \\
Matrix (resolution) & $256 \times 256$ & $256 \times 256$ & $256 \times 256$ \\
Flip Angle & $9^{\circ}$ & $\mathrm{T} 2$ variable & T2 variable \\
Turbo Factor (ETL) & 224 & 282 & 278 \\
Averages & 1 & 1 & 1 \\
\hline
\end{tabular}

Abbreviations: FLAIR: fluid-attenuated inversion recovery; TR: repetition time; TE: echo time; TI: inversion time; FOV: field-ofview; ETL: echo train length.

Cardiorespiratory fitness was assessed as $\mathrm{VO}_{2}$ $\left(\mathrm{mL} \cdot \mathrm{kg}^{-1} \cdot \mathrm{min}^{-1}\right)$ obtained with graded maximal exercise testing on a treadmill or an ergometer bicycle [81]. Participants with previous heart diseases were tested under ECG monitoring, and participants with known cardiovascular disease were tested according to the American College of Cardiology/American Heart Association guidelines for exercise testing of patients with known cardiovascular disease [82]. $V_{2} O_{2 m a x}$ is reached when the respiratory exchange ratio is $\geq 1.05$ and $\mathrm{VO}_{2}$ does not increase more than $2 \mathrm{~mL}$ between two 30 -second periods despite increased workload. If the participant was unable to meet the $\mathrm{VO}_{2 \max }$ criterion, $\mathrm{VO}_{2 \text { peak }}$ was estimated instead. $\mathrm{VO}_{2 \text { peak }}$ was calculated from the mean of the three highest $\mathrm{VO}_{2}$ measurements across a consecutive 10 second period. For participants with $\mathrm{VO}_{2 \max }$ this value was used while $\mathrm{VO}_{2 \text { peak }}$ was used for those who could not reach maximal oxygen uptake in this study. The term peak oxygen uptake $\left(\mathrm{VO}_{2 \text { peak }}\right)$ refers to the combination of these measures in this study.

\section{Magnetic resonance imaging}

\section{MRI acquisition}

Brain MR imaging was acquired on the same 3T Siemens Skyra scanner equipped with a 32-channel head coil. A standardized Generation 100 Study MRI protocol was used at all timepoints. In this study, the 3D T1-weighted, T2-weighted, and T2-weighted FLAIR scans were used (Table 10). The mean intervals (SD) between the MRI scans at baseline, one-, three-, and five-year follow-up were 475 (13) days, 628 (21) days, and 773 (33) days, respectively.

Manual and automated processing of brain MRI scans All image analysis was performed blinded for the participants' group adherence, demographic and clinical information. Manual segmentation of WMH was performed by delineating the hyperintense regions in WM on the FLAIR scans from the four different timepoints using the software Multi-image Analysis GUI (Mango) ver. 4.0.1 (http://rii.uthscsa.edu/mango/) and a Wacom Intuos pen tablet model CTL-480 (Wacom Co., Ltd., Saitama, Japan) (Figure 3). One rater performed the manual delineation at baseline and one-year follow-up and another rater at three- and five-year follow-up. To make segmentations comparable, rater 1 instructed rater 2, and $\mathrm{WMH}$ delineation in the first 25 scans from the threeyear follow up was performed side-by-side with already delineated WMH in the same brains at the one-year follow up. Each rater delineated WMH again in a random selection of ten participants, blinded for previous results by the same rater for intra-rater reliability analysis.

To investigate if certain regions of WMH were more sensitive to the effects of the intervention and/or $\mathrm{VO}_{2 \text { peak }}, \mathrm{WMH}$ were divided into PWMH and DWMH. Likewise, associations between intervention group and/or $\mathrm{VO}_{2 \text { peak, }}$ and automatically derived WMhypointensity volume from T1-weighted scans, which are considered to reflect more severely affected WMH regions [44, 83, 84], were assessed.

The flow of the image analysis pipeline after manual segmentation is depicted in Figure 4. From the manually assessed WMH mask, the total WMH volume and the volumes of PWMH and DWMH were obtained. For each participant, the PWMH and DWMH volumes were acquired at each timepoint by applying the lateral ventricular mask from the FreeSurfer analysis (v 6.0.02) of the 3D T1-weighted scans (http://surfer.nmr.mgh.harvard.edu/) [85] (Figure 4). The ventricular mask was rigid-body aligned from the 3D T1-weighted to the FLAIR scan in ANTS (v 2.3.1). 
Subsequently, the ventricular mask was morphologically dilated by $10 \mathrm{~mm}$ using the ImageMath program in ANTS (Figure 4). PWMH were WMH located within $10 \mathrm{~mm}$ from the ventricular edge, while DWMH were WMH located beyond $10 \mathrm{~mm}$ from the ventricular edge. The $10 \mathrm{~mm}$ cut off was chosen as it is widely used and provides a separation between $\mathrm{PWMH}$ and DWMH with regard to differences in the two regions' associations with cardiovascular risk factors, physiological parameters and cognitive scores $[13,86,87]$. The fit of the ventricular mask was visually quality assessed for all timepoints in all individuals.

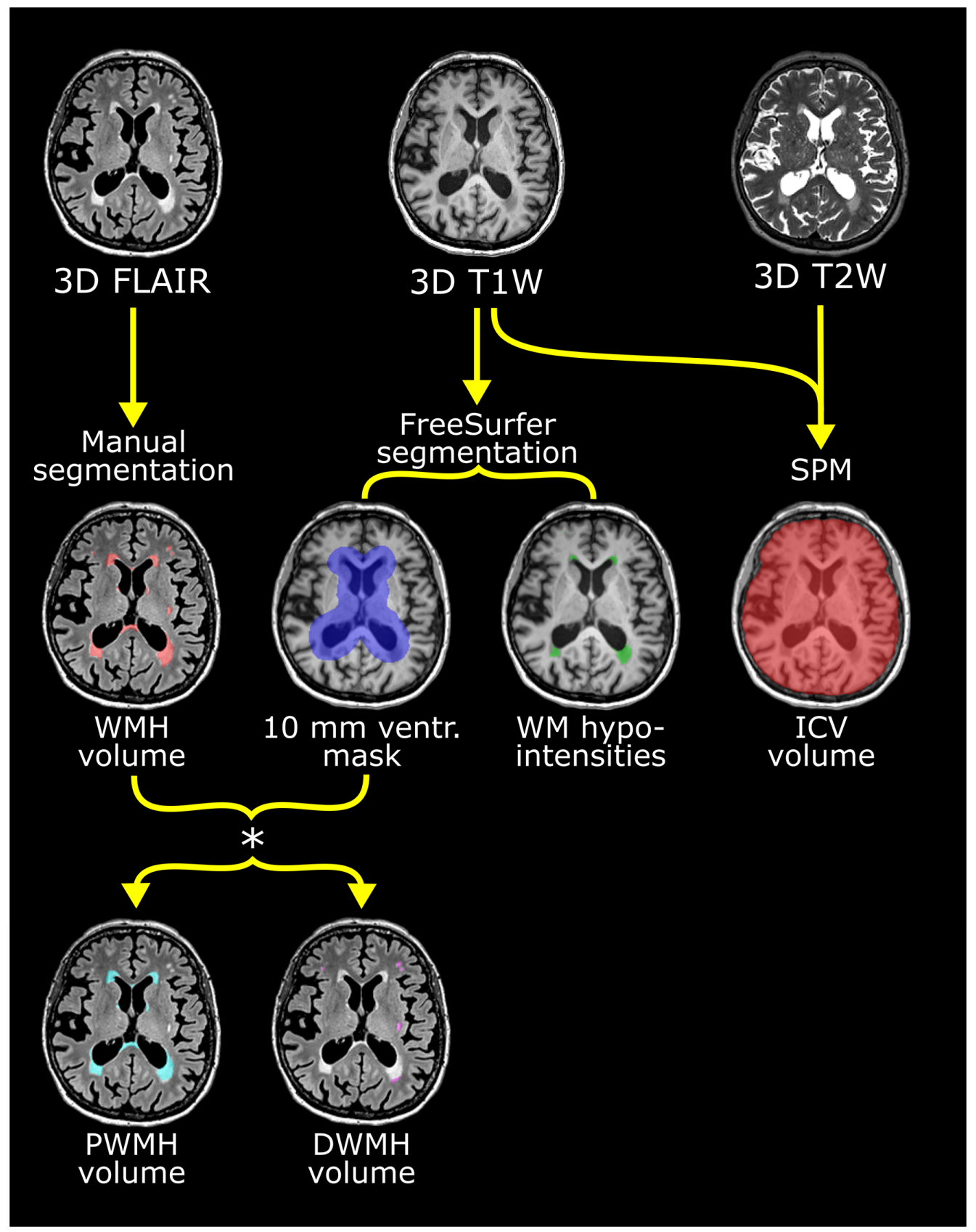

Figure 4. Flow chart of the multiparametric analysis of the brain MRI scans exemplified with scans from one participant. Upper row shows the 3D FLAIR, T1- and T2-weighted scans used. See Table 10 for scan details. Manual segmentation of white mater hyperintensities (WMH) was performed on the FLAIR images. From the T1-weighted scan, the ventricular (ventr.) mask derived with FreeSurfer (shown in violet in middle row) was used to stratify WMH into periventricular white mater hyperintensities (PWMH) (located $<10 \mathrm{~mm}$ from the ventricular edge) and deep white mater hyperintensities (DWMH) ( $\geq 10 \mathrm{~mm}$ from ventricular edge) as seen in the lower row. PWMH are depicted in cyan and DWMH in white. White matter (WM)-hypointensity volume was also derived from the FreeSurfer analysis (middle row) and shown as green lesions. Intracranial volume (ICV) was calculated from the T1- and T2-weighted scans using SPM. These segmentations were performed separately for the scans from baseline, one-, three- and five years. 
The total volume of white matter (WM)-hypointensity, reflecting white matter signal loss on the 3D T1-weighted scans, was obtained by automated segmentation for subcortical structures in FreeSurfer (v 6.0.0-2) (Figure 4).

Intracranial volume (ICV) was estimated in SPM8 (http://fil.ion.ucl.ac.uk/spm) with the automatic reverse brain mask method using the 3D T1- and T2-weighted scans [88] (Figure 4).

The WMH, PWMH, DWMH and WM-hypointensity volumes were normalized by dividing by ICV and multiplied by 1000 (i.e., \%o of ICV) to make the results more legible. The different WMH measurements were leftward skewed, also after scaling to ICV. The ICV corrected WMH measures were used in the statistical analysis since regression models do not require the dependent variables to be normally distributed.

\section{Statistical analysis}

\section{Demographic and clinical data}

Analyses of missing data were performed using Little's test of missing completely at random [89]. The test was performed for all variables.

Demographic and health characteristics at baseline are presented as mean (standard deviation) or median (interquartile range) based on the distribution of the variable. Group comparisons were performed with independent samples $t$-test, Mann-Whitney $U$-test, oneway ANOVA or Kruskal-Wallis test (with Dunn's test for post-hoc analyses) for continuous and ordinal variables, and Chi-Square-test or Fisher's exact test for categorical variables.

The development of $\mathrm{VO}_{2 \text { peak }}$ for all participants was assessed using a linear mixed model with $\mathrm{VO}_{2 \text { peak }}$ as the dependent variable, time and group and their interaction as fixed effects, with participant as a random effect, adjusting for sex, age, and the dependent variable (e.g., $\left.\mathrm{VO}_{2 \text { peak }}\right)$ at baseline as recommended by Twisk et al. [90] and Coffman et al. [91]. In this model, the coefficients for the interaction terms give the estimated intervention effects at year one, three, and five. After analysis, the normality of the residuals was checked by visual inspection of QQ-plots. Three residuals deviated from the normal distribution and were considered outliers. A sensitivity analysis excluding these observations gave similar results (data not shown).

\section{Intra- and inter-rater reliability}

For the ten manually delineated WMH, which were rated twice by the same rater, intra-rater reliability was assessed for each rater using intraclass correlation coefficient (ICC). ICC estimates and their 95\% confidence intervals were calculated based on single measurement, absolute-agreement, 2-way mixed-effects model. Interpretation of the ICC for intra-rater reliability was based on values from Portney and Watkins, where ICC values between 0.75 and 0.9 indicate good reliability, and values greater than 0.90 indicate excellent reliability [92].

The known correlation between WMH and WMhypointensity was used for assessment of the inter-rater reliability $[83,84]$. Inter-rater reliability was evaluated in a longitudinal linear mixed model analysis with total WM-hypointensity volume as outcome, and WMH volume at baseline, and after one-, three-, and five years of intervention, with rater, and interaction between rater and $\mathrm{WMH}$ volume included in the model. For the interrater assessment, the presence of a significant association between $\mathrm{WMH}$ and WM-hypointensity volume combined with no effect of rater on WMhypointensity volume nor interaction between rater and WMH volume, was interpreted as a good correlation between raters and lack of rater-specific effects.

\section{Intervention assessment; group effect}

We first investigated the effect of MICT and HIIT interventions compared to controls on $\mathrm{WMH}$ volume during the five-year RCT. We used a linear mixed model similar to the one previously described, but with total $\mathrm{WMH}$ volume normalized to $\mathrm{ICV}$, replacing $\mathrm{VO}_{2 \text { peak }}$ as the dependent variable. Similar linear mixed model analyses were subsequently performed with ICV normalized PWMH-, DWMH- and WM-hypointensity volume as dependent variables to assess if the intervention affected the two WMH regions and/or WM-hypointensity differently. The interaction between group and time was considered the main outcome and included in all analyses. Interactions between group, sex and age were also investigated based on findings in previous literature, but only retained in the model if significant. The normality of residuals for each linear mixed model performed was checked by visual inspection of QQ-plots. If a deviation from normality was observed, the analysis was repeated after removing observations that represented outliers. The analysis without outliers was performed for WMH, PWMH, DWMH and WM-hypointensity volumes. After removing outliers, analyses for $\mathrm{WMH}, \mathrm{PWMH}$ and WM-hypointensity volume analyses gave similar results (data not shown), and hence only results from the main model were reported. For DWMH, three residuals were confirmed as outliers and the corresponding observations were excluded in the final model which was reported.

In accordance with the main RCT analysis [27], an additional analysis using the aforementioned linear 
mixed model was applied with a combined supervised exercise group (MICT\&HIIT versus controls) as fixed effect instead of including the MICT and HIIT groups separately.

\section{Intervention assessment; $\mathrm{VO}_{2 \text { peak }}$ effects}

To evaluate the effect of $\mathrm{VO}_{2 \text { peak }}$ on $\mathrm{WMH}$ volume across the intervention period, $\mathrm{VO}_{2 \text { peak }}$ at each timepoint was added to the previously described linear mixed model with WMH as dependent variable. Group and the interaction between group and time were excluded as no effect of group on $\mathrm{VO}_{2 \text { peak }}$ was uncovered. The analysis was repeated with PWMH, DWMH and WMhypointensity as dependent variables. To correct for baseline $\mathrm{VO}_{2 \text { peak }}$, each participant's four $\mathrm{VO}_{2 \text { peak }}$ values was subtracted by the baseline-value (e.g., one-year follow-up minus baseline value, three-year follow-up minus baseline value, etc.). Correcting for baseline $\mathrm{VO}_{2 \text { peak }}$ did not alter the results and was therefore removed from the final model. All analyses were tested for interactions between $\mathrm{VO}_{2 \text { peak, }}$ age, and sex. There were no significant interactions, and they were therefore not included in the final model.

To evaluate the effect of changing $\mathrm{VO}_{2 \text { peak }}$ on changing $\mathrm{WMH}$ volume across the intervention, we used the 'model of changes' described by Twisk as a more sensitive method for uncovering change over time [64]. Subjects were included as a random effect, and age and sex as the fixed effects. Yearly change in $\mathrm{WMH}$ and $\mathrm{VO}_{2 \text { peak }}$ was calculated by subtracting the former year's value from the following one (e.g., oneyear follow-up minus baseline value, etc.). As there were two years between the two last follow-ups, the delta was therefore divided by two to get the 'yearly' change in values. The analysis was repeated with PWMH, DWMH and WM-hypointensity volumes as dependent variables. All the models were tested for interactions between $\mathrm{VO}_{2 \text { peak, }}$ age and sex. There were no significant interactions, and the final model was applied without interactions.

Finally, we examined if baseline $\mathrm{VO}_{2 \text { peak }}$ were correlated with overall WMH change over five years (five-year WMH volume minus baseline WMH volume) using a linear regression model with five-year change in WMH volume as dependent variable and baseline $\mathrm{VO}_{2 \text { peak }}$ as covariate, adjusted for age and sex.

\section{Supplemental analysis including risk factors for $\mathrm{WMH}$}

Other factors related to $\mathrm{WMH}$ and physical activity/fitness, such as current smoking, hypertension, BMI and HADS score were added to the linear mixed models assessing effects of group and $\mathrm{VO}_{2 \text { peak }}$ on WMH, PWMH, DWMH and WM-hypointensity volume, as some studies report these factors to affect the relationship between WMH and physical activity/ fitness measures $[17,18]$.

The threshold for statistical significance was set to $p<$ 0.05 . Correction for multiple hypotheses was not done since this is the first five-year exercise intervention study implementing supervised MICT and HIIT interventions and avoiding type 2 errors is important in this setting. The analyses were carried out in SPSS version 27.

\section{Abbreviations}

AIC: Akaike's information criterion; ANOVA: analysis of variance; BDNF: brain-derived neurotrophic factor; BP: blood pressure; CI: confidence interval; DBP: diastolic blood pressure; DWMH: deep white matter hyperintensities; ECG: electrocardiogram; ETL: echo train length; FLAIR: fluid-attenuated inversion recovery; FOV: field-of-view; G100: The Generation 100 Study; HADS: Hospital Anxiety and Depression Scale; HbA1c: glycosylated hemoglobin; HDL: high-density lipoprotein; HIIT: high-intensity interval training; hsCRP: high-sensitive c-reactive protein; ICC: intraclass correlation coefficient; ICV: intracranial volume; IQR: interquartile range; LDL: low-density lipoprotein; MET: metabolic equivalent of task; MICT: moderate-intensity continuous training; MoCA: Montreal Cognitive Assessment; MRI: magnetic resonance imaging; NS: not significant; PWMH: periventricular white matter hyperintensities; RCT: randomized controlled trial; SBP: systolic blood pressure; SD: standard deviation; TE: echo time; TG: triglycerides; TI: inversion time; TR: repetition time; T1W: T1-weighted; T2W: T2-weighted; $\mathrm{VO}_{2 \text { max }}$ : maximal oxygen uptake; $\mathrm{VO}_{2 \text { peak: peak oxygen }}$ uptake; WM: white matter; WMH: white matter hyperintensities.

\section{AUTHOR CONTRIBUTIONS}

Anette Arild: Data collection; WMH delineation; Data curation; Visualization; Formal analysis; Original draft; Revisions. Torgil Vangberg: Formal analysis; Methodology; Supervision; Visualization; Writing review and editing. Hanne Nikkels: Data collection/Investigation, WMH delineation; Data curation; Writing - review and editing. Stian Lydersen: Formal analysis; Methodology; Writing - review and editing Ulrik Wisløff: Funding acquisition, Writing review and editing Dorthe Stensvold: Data curation; Funding acquisition; Investigation; Project administration; Resources; Supervision; Writing review and editing. Asta K. Håberg: Data curation; Funding acquisition; Investigation; Methodology; Project administration; Resources; Supervision; Roles/Writing - original draft; review and editing. 


\section{ACKNOWLEDGMENTS}

The authors thank all the participants for taking part in the study. We thank Torill E. Sjøbakk for help with participant scheduling, and our master student Stine Bjøralt for help with data collection, and Professor Jos W.R. Twisk for his insights into the statistical analysis. We thank PhD Line Skarsem Reitlo for help with the activity questionnaires. We are also grateful to those involved with the clinical testing, including $\mathrm{VO}_{2 \text { peak }}$ performed at the core facility NeXt Move, NTNU, and the Clinical Research Facility, St. Olav's Hospital.

\section{CONFLICTS OF INTEREST}

The authors declare no conflicts of interest related to this study.

\section{FUNDING}

The G100 Study was supported by the Research Council of Norway, The K.G. Jebsen Foundation for medical research, Norway, NTNU, Central Norway Regional Health Authority, St. Olav's Hospital, Trondheim, Norway, and The National Association for Public Health, Norway. The cognitive data collection was supported by Norwegian Advisory Unit for fMRI, Department of Radiology and Nuclear Medicine, St. Olav's Hospital, Trondheim. Ms. Arild has received funding from The Royal Norwegian Society of Sciences and Letters (I.K. Lykkes foundation) and The Medical Student Research Program Foundation at the Faculty of Medicine and Health Sciences, NTNU.

\section{REFERENCES}

1. Håberg AK, Hammer TA, Kvistad KA, Rydland J, Müller $T B$, Eikenes L, Gårseth $M$, Stovner LJ. Incidental Intracranial Findings and Their Clinical Impact; The HUNT MRI Study in a General Population of 1006 Participants between 50-66 Years. PLoS One. 2016; 11:e0151080.

https://doi.org/10.1371/journal.pone.0151080 PMID:26950220

2. de Leeuw FE, de Groot JC, Achten E, Oudkerk M, Ramos LM, Heijboer R, Hofman A, Jolles J, van Gijn J, Breteler MM. Prevalence of cerebral white matter lesions in elderly people: a population based magnetic resonance imaging study. The Rotterdam Scan Study. J Neurol Neurosurg Psychiatry. 2001; 70:9-14.

https://doi.org/10.1136/jnnp.70.1.9

PMID: 11118240

3. Briley DP, Wasay M, Sergent S, Thomas S. Cerebral white matter changes (leukoaraiosis), stroke, and gait disturbance. J Am Geriatr Soc. 1997; 45:1434-8. https://doi.org/10.1111/j.1532-5415.1997.tb03192.x PMID:9400551

4. Kreisel SH, Blahak $C$, Bäzner $H$, Inzitari D, Pantoni L, Poggesi A, Chabriat H, Erkinjuntti T, Fazekas F, Ferro JM, Langhorne P, O'Brien J, Scheltens $P$, et al. Deterioration of gait and balance over time: the effects of age-related white matter change--the LADIS study. Cerebrovasc Dis. 2013; 35:544-53.

https://doi.org/10.1159/000350725

PMID:23838682

5. Jokinen $\mathrm{H}$, Gonçalves N, Vigário R, Lipsanen J, Fazekas F, Schmidt R, Barkhof F, Madureira S, Verdelho A, Inzitari D, Pantoni L, Erkinjuntti T, and LADIS Study Group. Early-Stage White Matter Lesions Detected by Multispectral MRI Segmentation Predict Progressive Cognitive Decline. Front Neurosci. 2015; 9:455.

https://doi.org/10.3389/fnins.2015.00455 PMID:26696814

6. Herrmann LL, Le Masurier M, Ebmeier KP. White matter hyperintensities in late life depression: a systematic review. J Neurol Neurosurg Psychiatry. 2008; 79:619-24. https://doi.org/10.1136/innp.2007.124651 PMID:17717021

7. Debette S, Markus HS. The clinical importance of white matter hyperintensities on brain magnetic resonance imaging: systematic review and metaanalysis. BMJ. 2010; 341:c3666.

https://doi.org/10.1136/bmj.c3666 PMID:20660506

8. Armstrong NJ, Mather KA, Sargurupremraj M, Knol MJ, Malik R, Satizabal CL, Yanek LR, Wen W, Gudnason VG, Dueker ND, Elliott LT, Hofer E, Bis J, et al. Common Genetic Variation Indicates Separate Causes for Periventricular and Deep White Matter Hyperintensities. Stroke. 2020; 51:2111-21. https://doi.org/10.1161/STROKEAHA.119.027544 PMID: $\underline{32517579}$

9. Anderson VC, Obayashi JT, Kaye JA, Quinn JF, Berryhill $P$, Riccelli LP, Peterson D, Rooney WD. Longitudinal relaxographic imaging of white matter hyperintensities in the elderly. Fluids Barriers CNS. 2014; $11: 24$.

https://doi.org/10.1186/2045-8118-11-24 PMID:25379172

10. Kim KW, MacFall JR, Payne ME. Classification of white matter lesions on magnetic resonance imaging in elderly persons. Biol Psychiatry. 2008; 64:273-80. https://doi.org/10.1016/j.biopsych.2008.03.024 PMID: $\underline{18471801}$

11. Salvadó $\mathrm{G}$, Brugulat-Serrat $A$, Sudre $\mathrm{CH}$, Grau-Rivera O, Suárez-Calvet M, Falcon C, Fauria K, Cardoso MJ, 
Barkhof F, Molinuevo JL, Gispert JD, and ALFA Study. Spatial patterns of white matter hyperintensities associated with Alzheimer's disease risk factors in a cognitively healthy middle-aged cohort. Alzheimers Res Ther. 2019; 11:12.

https://doi.org/10.1186/s13195-018-0460-1

PMID:30678723

12. Smith $C D$, Johnson ES, Van Eldik $\amalg$, Jicha GA, Schmitt FA, Nelson PT, Kryscio RJ, Murphy RR, Wellnitz CV. Peripheral (deep) but not periventricular MRI white matter hyperintensities are increased in clinical vascular dementia compared to Alzheimer's disease. Brain Behav. 2016; 6:e00438.

https://doi.org/10.1002/brb3.438 PMID:26925303

13. Griffanti L, Jenkinson M, Suri S, Zsoldos E, Mahmood A, Filippini N, Sexton CE, Topiwala A, Allan C, Kivimäki $M$, Singh-Manoux A, Ebmeier KP, Mackay $C E$, Zamboni G. Classification and characterization of periventricular and deep white matter hyperintensities on MRI: A study in older adults. Neuroimage. 2018; 170:174-81.

https://doi.org/10.1016/i.neuroimage.2017.03.024 PMID:28315460

14. Veldsman M, Kindalova P, Husain M, Kosmidis I, Nichols TE. Spatial distribution and cognitive impact of cerebrovascular risk-related white matter hyperintensities. Neuroimage Clin. 2020; 28:102405. https://doi.org/10.1016/j.nicl.2020.102405 PMID:32971464

15. Zhao Y, Ke Z, He W, Cai Z. Volume of white matter hyperintensities increases with blood pressure in patients with hypertension. J Int Med Res. 2019; 47:3681-9.

https://doi.org/10.1177/0300060519858023 PMID:31242795

16. Dickie DA, Ritchie SJ, Cox SR, Sakka E, Royle NA, Aribisala BS, Valdés Hernández MC, Maniega SM, Pattie A, Corley J, Starr JM, Bastin ME, Deary IJ, Wardlaw JM. Vascular risk factors and progression of white matter hyperintensities in the Lothian Birth Cohort 1936. Neurobiol Aging. 2016; 42:116-23. https://doi.org/10.1016/i.neurobiolaging.2016.03.011 PMID:27143428

17. Sexton CE, Betts JF, Demnitz N, Dawes H, Ebmeier KP, Johansen-Berg $\mathrm{H}$. A systematic review of MRI studies examining the relationship between physical fitness and activity and the white matter of the ageing brain. Neuroimage. 2016; 131:81-90.

https://doi.org/10.1016/j.neuroimage.2015.09.071 PMID:26477656

18. Torres ER, Strack EF, Fernandez CE, Tumey TA, Hitchcock ME. Physical Activity and White Matter
Hyperintensities: A Systematic Review of Quantitative Studies. Prev Med Rep. 2015; 2:319-25.

https://doi.org/10.1016/j.pmedr.2015.04.013 PMID:26046015

19. Johnson NF, Bahrani AA, Powell DK, Jicha GA, Gold BT. Cardiorespiratory fitness diminishes the effects of age on white matter hyperintensity volume. PLoS One. 2020; 15:e0236986.

https://doi.org/10.1371/journal.pone.0236986 PMID:32866198

20. Vesperman CJ, Pozorski V, Dougherty RJ, Law LL, Boots E, Oh JM, Gallagher CL, Carlsson CM, Rowley HA, Ma Y, Bendlin BB, Asthana S, Sager MA, et al. Cardiorespiratory fitness attenuates age-associated aggregation of white matter hyperintensities in an atrisk cohort. Alzheimers Res Ther. 2018; 10:97.

https://doi.org/10.1186/s13195-018-0429-0

PMID:30249285

21. Voss MW, Weng TB, Burzynska $A Z$, Wong CN, Cooke GE, Clark R, Fanning J, Awick E, Gothe NP, Olson EA, McAuley E, Kramer AF. Fitness, but not physical activity, is related to functional integrity of brain networks associated with aging. Neuroimage. 2016; 131:113-25.

https://doi.org/10.1016/i.neuroimage.2015.10.044 PMID:26493108

22. Dao E, Barha CK, Best JR, Hsiung GY, Tam R, LiuAmbrose T. The Effect of Aerobic Exercise on White Matter Hyperintensity Progression May Vary by Sex. Can J Aging. 2019; 38:236-44. https://doi.org/10.1017/S0714980818000582 PMID:30867079

23. Stephen R, Ngandu T, Liu Y, Peltonen M, Antikainen R, Kemppainen N, Laatikainen $T$, Lötjönen J, Rinne J, Strandberg T, Tuomilehto J, Vanninen R, Soininen H, et al, and FINGER Study Group. Change in CAIDE Dementia Risk Score and Neuroimaging Biomarkers During a 2Year Multidomain Lifestyle Randomized Controlled Trial: Results of a Post-Hoc Subgroup Analysis. J Gerontol A Biol Sci Med Sci. 2021; 76:1407-14. https://doi.org/10.1093/gerona/glab130 PMID:33970268

24. Venkatraman VK, Sanderson A, Cox KL, Ellis KA, Steward C, Phal PM, Gorelik A, Sharman MJ, Villemagne VL, Lai M, Cyarto EV, Merkel B, Ames D, et al. Effect of a 24-month physical activity program on brain changes in older adults at risk of Alzheimer's disease: the AIBL active trial. Neurobiol Aging. 2020; 89:132-41.

https://doi.org/10.1016/j.neurobiolaging.2019.02.030 PMID:31324405

25. Lucas SJ, Cotter JD, Brassard P, Bailey DM. Highintensity interval exercise and cerebrovascular health: 
curiosity, cause, and consequence. J Cereb Blood Flow Metab. 2015; 35:902-11.

https://doi.org/10.1038/jcbfm.2015.49

PMID:25833341

26. Moon SY, de Souto Barreto $P$, Cesari $M$, Chupin $M$, Mangin JF, Bouyahia A, Fillon L, Andrieu S, Vellas B. Physical Activity and Changes in White Matter Hyperintensities over Three Years. J Nutr Health Aging. 2018; 22:425-30.

https://doi.org/10.1007/s12603-017-0959-3

PMID:29484357

27. Stensvold D, Viken H, Steinshamn SL, Dalen H, Støylen A, Loennechen JP, Reitlo LS, Zisko N, Bækkerud FH, Tari AR, Sandbakk SB, Carlsen T, Ingebrigtsen JE, et al. Effect of exercise training for five years on all cause mortality in older adults-the Generation 100 study: randomised controlled trial. BMJ. 2020; 371:m3485.

https://doi.org/10.1136/bmj.m3485

PMID:33028588

28. Stensvold D, Viken H, Rognmo $\varnothing$, Skogvoll $E$, Steinshamn S, Vatten LJ, Coombes JS, Anderssen SA, Magnussen J, Ingebrigtsen JE, Fiatarone Singh MA, Langhammer A, Støylen A, et al. A randomised controlled study of the long-term effects of exercise training on mortality in elderly people: study protocol for the Generation 100 study. BMJ Open. 2015; 5:e007519.

https://doi.org/10.1136/bmjopen-2014-007519 PMID:25678546

29. Stephen R, Liu Y, Ngandu T, Antikainen R, Hulkkonen J, Koikkalainen J, Kemppainen N, Lötjönen J, Levälahti E, Parkkola R, Pippola P, Rinne J, Strandberg T, et al, and FINGER study group. Brain volumes and cortical thickness on MRI in the Finnish Geriatric Intervention Study to Prevent Cognitive Impairment and Disability (FINGER). Alzheimers Res Ther. 2019; 11:53. https://doi.org/10.1186/s13195-019-0506-z PMID: $\underline{31164160}$

30. Sokołowski DR, Hansen TI, Rise HH, Reitlo LS, Wisløff $U$, Stensvold D, Håberg AK. 5 Years of Exercise Intervention Did Not Benefit Cognition Compared to the Physical Activity Guidelines in Older Adults, but Higher Cardiorespiratory Fitness Did. A Generation 100 Substudy. Front Aging Neurosci. 2021; 13:742587.

https://doi.org/10.3389/fnagi.2021.742587 PMID: 34867275

31. Podewils LJ, Guallar E, Beauchamp N, Lyketsos CG, Kuller LH, Scheltens P. Physical activity and white matter lesion progression: assessment using MRI. Neurology. 2007; 68:1223-6.

https://doi.org/10.1212/01.wnl.0000259063.50219.3e PMID: 17420407
32. Blanco PJ, Müller LO, Spence JD. Blood pressure gradients in cerebral arteries: a clue to pathogenesis of cerebral small vessel disease. Stroke Vasc Neurol. 2017; 2:108-17.

https://doi.org/10.1136/svn-2017-000087

PMID:28989801

33. De Reuck J. The human periventricular arterial blood supply and the anatomy of cerebral infarctions. Eur Neurol. 1971; 5:321-34.

https://doi.org/10.1159/000114088

PMID:ㅍ141149

34. Hall KS, Hyde ET, Bassett DR, Carlson SA, Carnethon MR, Ekelund U, Evenson KR, Galuska DA, Kraus WE, Lee IM, Matthews CE, Omura JD, Paluch AE, et al. Systematic review of the prospective association of daily step counts with risk of mortality, cardiovascular disease, and dysglycemia. Int J Behav Nutr Phys Act. 2020; 17:78.

https://doi.org/10.1186/s12966-020-00978-9

PMID:32563261

35. Kodama S, Saito K, Tanaka S, Maki M, Yachi Y, Asumi M, Sugawara A, Totsuka K, Shimano H, Ohashi $Y$, Yamada N, Sone H. Cardiorespiratory fitness as a quantitative predictor of all-cause mortality and cardiovascular events in healthy men and women: a meta-analysis. JAMA. 2009; 301:2024-35.

https://doi.org/10.1001/jama.2009.681

PMID:19454641

36. Zhang X, Cash RE, Bower JK, Focht BC, Paskett ED. Physical activity and risk of cardiovascular disease by weight status among U.S adults. PLoS One. 2020; 15:e0232893.

https://doi.org/10.1371/journal.pone.0232893

PMID:32384119

37. Pani J, Reitlo LS, Evensmoen HR, Lydersen S, Wisløff U, Stensvold D, Håberg AK. Effect of 5 Years of Exercise Intervention at Different Intensities on Brain Structure in Older Adults from the General Population: A Generation 100 Substudy. Clin Interv Aging. 2021; 16:1485-501. https://doi.org/10.2147/CIA.S318679 PMID:34408409

38. Milanović Z, Sporiš G, Weston M. Effectiveness of High-Intensity Interval Training (HIT) and Continuous Endurance Training for VO2max Improvements: A Systematic Review and Meta-Analysis of Controlled Trials. Sports Med. 2015; 45:1469-81. https://doi.org/10.1007/s40279-015-0365-0 PMID:26243014

39. Loe H, Rognmo $\varnothing$, Saltin B, Wisløff U. Aerobic capacity reference data in 3816 healthy men and women 2090 years. PLoS One. 2013; 8:e64319. https://doi.org/10.1371/journal.pone.0064319 PMID:23691196 
40. Espeland MA, Erickson $K$, Neiberg RH, Jakicic JM, Wadden TA, Wing RR, Desiderio L, Erus G, Hsieh MK, Davatzikos C, Maschak-Carey BJ, Laurienti PJ, DemosMcDermott K, Bryan RN, and Action for Health in Diabetes Brain Magnetic Resonance Imaging (Look AHEAD Brain) Ancillary Study Research Group. Brain and White Matter Hyperintensity Volumes After 10 Years of Random Assignment to Lifestyle Intervention. Diabetes Care. 2016; 39:764-71.

https://doi.org/10.2337/dc15-2230 PMID:27208378

41. Kellar D, Lockhart SN, Aisen P, Raman R, Rissman RA, Brewer J, Craft S. Intranasal Insulin Reduces White Matter Hyperintensity Progression in Association with Improvements in Cognition and CSF Biomarker Profiles in Mild Cognitive Impairment and Alzheimer's Disease. J Prev Alzheimers Dis. 2021; 8:240-8. https://doi.org/10.14283/jpad.2021.14 PMID: $\underline{34101779}$

42. Lai Y, Jiang C, Du X, Sang C, Guo X, Bai R, Tang R, Dong $J$, Ma C. Effect of intensive blood pressure control on the prevention of white matter hyperintensity: Systematic review and meta-analysis of randomized trials. J Clin Hypertens (Greenwich). 2020; 22:1968-73. https://doi.org/10.1111/jch.14030 PMID: $\underline{3459521}$

43. Zhou D, Ding J, Asmaro K, Pan L, Ya J, Yang Q, Fan C, Ding $Y$, Ji $X$, Meng R. Clinical Characteristics and Neuroimaging Findings in Internal Jugular Venous Outflow Disturbance. Thromb Haemost. 2019; 119:308-18.

https://doi.org/10.1055/s-0038-1676815 PMID:30605919

44. Hotz I, Deschwanden PF, Liem F, Mérillat S, Kollias S, Jäncke $L$. Validation and comparison of three freely available methods for extracting white matter hyperintensities: FreeSurfer, UBO Detector and BIANCA. bioRxiv. 2020. https://doi.org/10.1101/2020.10.17.343574

45. Melazzini L, Vitali $P$, Olivieri E, Bolchini $M$, Zanardo $M$, Savoldi F, Di Leo G, Griffanti L, Baselli G, Sardanelli F, Codari M. White Matter Hyperintensities Quantification in Healthy Adults: A Systematic Review and Meta-Analysis. J Magn Reson Imaging. 2021; 53:1732-43.

https://doi.org/10.1002/imri.27479 PMID:33345393

46. Adachi M, Sato T. Characterization of the Growth of Deep and Subcortical White Matter Hyperintensity on MR Imaging: A Retrospective Cohort Study. Magn Reson Med Sci. 2017; 16:238-44.

https://doi.org/10.2463/mrms.mp.2016-0063 PMID:28090008
47. Jiaerken $Y$, Luo $X, Y u X$, Huang $P, X u X$, Zhang $M$, and Alzheimer's Disease Neuroimaging Initiative (ADNI). Microstructural and metabolic changes in the longitudinal progression of white matter hyperintensities. J Cereb Blood Flow Metab. 2019; 39:1613-22.

https://doi.org/10.1177/0271678X18761438

PMID:29519198

48. Maillard P, Carmichael O, Harvey D, Fletcher E, Reed B, Mungas D, DeCarli C. FLAIR and diffusion MRI signals are independent predictors of white matter hyperintensities. AJNR Am J Neuroradiol. 2013; 34:54-61.

https://doi.org/10.3174/ajnr.A3146

PMID:22700749

49. Burzynska AZ, Chaddock-Heyman L, Voss MW, Wong CN, Gothe NP, Olson EA, Knecht A, Lewis A, Monti JM, Cooke GE, Wojcicki TR, Fanning J, Chung HD, et al. Physical activity and cardiorespiratory fitness are beneficial for white matter in low-fit older adults. PLoS One. 2014; 9:e107413.

https://doi.org/10.1371/journal.pone.0107413 PMID:25229455

50. van den Heuvel DM, ten Dam VH, de Craen AJ, Admiraal-Behloul $F$, Olofsen $H$, Bollen EL, Jolles J, Murray HM, Blauw GJ, Westendorp RG, van Buchem MA. Increase in periventricular white matter hyperintensities parallels decline in mental processing speed in a non-demented elderly population. J Neurol Neurosurg Psychiatry. 2006; 77:149-53. https://doi.org/10.1136/jnnp.2005.070193 PMID:16421114

51. van Leijsen EMC, Bergkamp $\mathrm{MI}$, van Uden IWM, Ghafoorian M, van der Holst HM, Norris DG, Platel B, Tuladhar AM, de Leeuw FE. Progression of White Matter Hyperintensities Preceded by Heterogeneous Decline of Microstructural Integrity. Stroke. 2018; 49:1386-93.

https://doi.org/10.1161/STROKEAHA.118.020980 PMID:29724890

52. Wardlaw JM, Chappell FM, Valdés Hernández MDC, Makin SDJ, Staals J, Shuler K, Thrippleton MJ, Armitage PA, Muñoz-Maniega S, Heye AK, Sakka E, Dennis MS. White matter hyperintensity reduction and outcomes after minor stroke. Neurology. 2017; 89:1003-10.

https://doi.org/10.1212/WNL.0000000000004328 PMID:28794252

53. Kreisel SH, Blahak C, Bäzner H, Hennerici MG. Does being physically active prevent future disability in older people? Attenuated effects when taking timedependent confounders into account. BMC Geriatr. 2017; 17:290. 
https://doi.org/10.1186/s12877-017-0657-3

PMID:29268707

54. Di Liegro CM, Schiera G, Proia P, Di Liegro I. Physical Activity and Brain Health. Genes (Basel). 2019; 10:720.

https://doi.org/10.3390/genes 10090720

PMID:31533339

55. Vangberg TR, Eikenes L, Håberg AK. The effect of white matter hyperintensities on regional brain volumes and white matter microstructure, a population-based study in HUNT. Neuroimage. 2019; 203:116158.

https://doi.org/10.1016/j.neuroimage.2019.116158 PMID:31493533

56. Niu H, Álvarez-Álvarez I, Guillén-Grima F, AguinagaOntoso I. Prevalence and incidence of Alzheimer's disease in Europe: A meta-analysis. Neurologia. 2017; 32:523-32.

https://doi.org/10.1016/j.nrl.2016.02.016 PMID:27130306

57. Gow AJ, Bastin ME, Muñoz Maniega S, Valdés Hernández MC, Morris Z, Murray C, Royle NA, Starr JM, Deary IJ, Wardlaw JM. Neuroprotective lifestyles and the aging brain: activity, atrophy, and white matter integrity. Neurology. 2012; 79:1802-8. https://doi.org/10.1212/WNL.0b013e3182703fd2 PMID:23091073

58. Moniruzzaman M, Kadota A, Segawa H, Kondo K, Torii S, Miyagawa N, Fujiyoshi A, Hisamatsu T, Watanabe Y, Shiino A, Nozaki K, Ueshima H, Miura K, and SESSA Research Group. Relationship Between Step Counts and Cerebral Small Vessel Disease in Japanese Men. Stroke. 2020; 51:3584-91. https://doi.org/10.1161/STROKEAHA.120.030141 PMID:33148144

59. Raichlen DA, Klimentidis YC, Bharadwaj PK, Alexander GE. Differential associations of engagement in physical activity and estimated cardiorespiratory fitness with brain volume in middle-aged to older adults. Brain Imaging Behav. 2020; 14:1994-2003. https://doi.org/10.1007/s11682-019-00148-x PMID:31209836

60. Commowick $O$, Istace $A$, Kain $M$, Laurent $B$, Leray $F$, Simon M, Pop SC, Girard P, Améli R, Ferré JC, Kerbrat A, Tourdias T, Cervenansky F, et al. Objective Evaluation of Multiple Sclerosis Lesion Segmentation using a Data Management and Processing Infrastructure. Sci Rep. 2018; 8:13650. https://doi.org/10.1038/s41598-018-31911-7 PMID: $\underline{30209345}$

61. Gouw AA, van der Flier WM, van Straaten EC, Pantoni L, Bastos-Leite AJ, Inzitari D, Erkinjuntti T, Wahlund
LO, Ryberg C, Schmidt R, Fazekas F, Scheltens P, Barkhof $F$, and LADIS study group. Reliability and sensitivity of visual scales versus volumetry for evaluating white matter hyperintensity progression. Cerebrovasc Dis. 2008; 25:247-53.

https://doi.org/10.1159/000113863

PMID: 18216467

62. Guo C, Niu K, Luo Y, Shi L, Wang Z, Zhao M, Wang D, Zhu W, Zhang $H$, Sun L. Intra-Scanner and InterScanner Reproducibility of Automatic White Matter Hyperintensities Quantification. Front Neurosci. 2019; 13:679.

https://doi.org/10.3389/fnins.2019.00679 PMID:31354406

63. Prins ND, van Straaten EC, van Dijk EJ, Simoni $M$, van Schijndel RA, Vrooman HA, Koudstaal PJ, Scheltens P, Breteler MM, Barkhof $F$. Measuring progression of cerebral white matter lesions on MRI: visual rating and volumetrics. Neurology. 2004; 62:1533-9. https://doi.org/10.1212/01.wnl.0000123264.40498.b6 PMID:15136677

64. Twisk JWR. Applied Longitudinal Data Analysis for Epidemiology. 2nd ed. Cambridge: Cambridge University Press; 2013. https://doi.org/10.1017/CBO9781139342834

65. Fleischman DA, Yang J, Arfanakis K, Arvanitakis Z, Leurgans SE, Turner AD, Barnes LL, Bennett DA, Buchman AS. Physical activity, motor function, and white matter hyperintensity burden in healthy older adults. Neurology. 2015; 84:1294-300.

https://doi.org/10.1212/WNL.0000000000001417 PMID:25762710

66. Franchetti MK, Bharadwaj PK, Nguyen LA, Van Etten EJ, Klimentidis YC, Hishaw GA, Trouard TP, Raichlen DA, Alexander GE. Interaction of Age and Selfreported Physical Sports Activity on White Matter Hyperintensity Volume in Healthy Older Adults. Front Aging Neurosci. 2020; 12:576025.

https://doi.org/10.3389/fnagi.2020.576025

PMID:33240074

67. Gu Y, Beato JM, Amarante E, Chesebro AG, Manly JJ, Schupf N, Mayeux RP, Brickman AM. Assessment of Leisure Time Physical Activity and Brain Health in a Multiethnic Cohort of Older Adults. JAMA Netw Open. 2020; 3:e2026506.

https://doi.org/10.1001/jamanetworkopen.2020.26506 PMID:33211111

68. Sen A, Gider $P$, Cavalieri $M$, Freudenberger $P$, Farzi $A$, Schallert M, Reichmann F, Watzinger N, Zweiker R, Schmidt $R$, Schmidt $H$. Association of cardiorespiratory fitness and morphological brain changes in the elderly: results of the Austrian Stroke Prevention Study. Neurodegener Dis. 2012; 10:135-7. 
https://doi.org/10.1159/000334760

PMID:22269924

69. Statistics Norway. Long-term illness. Disease, injury or impairment, by sex and age (per cent) 1998-2019. Oslo, Norway: Statistisk sentralbyrå; 2019. Report No.: 11190. Available from: https://www.ssb.no/en/statbank/table/11190/

70. Statistics Norway. Lifestyle habits, by sex and age (per cent) 1998-2019. Oslo, Norway: Statistisk sentralbyrå; 2019. Report No.: 06181. Available from: https://www.ssb.no/en/statbank/table/06181/

71. Rovio S, Spulber G, Nieminen L, Niskanen E, Winblad B, Tuomilehto J, Nissinen A, Soininen H, Kivipelto M. The effect of midlife physical activity on structural brain changes in the elderly. Neurobiol Aging. 2010; 31:1927-36.

https://doi.org/10.1016/j.neurobiolaging.2008.10.007 PMID:19062136

72. Helsedirektoratet. Fysisk aktivitet; Aktivitetshåndboken 2011. Oslo: Helsedirektoratet; 2011. Available from: https://www.helsedirektoratet.no/tema/fysiskaktivitet

73. Borg GA. Psychophysical bases of perceived exertion. Med Sci Sports Exerc. 1982; 14:377-81. https://doi.org/10.1249/00005768-198205000-00012 PMID:7154893

74. Godin O, Tzourio C, Maillard P, Mazoyer B, Dufouil C. Antihypertensive treatment and change in blood pressure are associated with the progression of white matter lesion volumes: the Three-City (3C)-Dijon Magnetic Resonance Imaging Study. Circulation. 2011; 123:266-73.

https://doi.org/10.1161/CIRCULATIONAHA.110.961052 PMID:21220733

75. American Diabetes Association. 2. Classification and Diagnosis of Diabetes: Standards of Medical Care in Diabetes-2020. Diabetes Care. 2020; 43:S14-31. https://doi.org/10.2337/dc20-S002 PMID:31862745

76. Unger T, Borghi C, Charchar F, Khan NA, Poulter NR, Prabhakaran D, Ramirez A, Schlaich M, Stergiou GS, Tomaszewski M, Wainford RD, Williams B, Schutte AE. 2020 International Society of Hypertension global hypertension practice guidelines. J Hypertens. 2020; 38:982-1004.

https://doi.org/10.1097/HJH.0000000000002453 PMID:32371787

77. Mykletun A, Stordal E, Dahl AA. Hospital Anxiety and Depression (HAD) scale: factor structure, item analyses and internal consistency in a large population. Br J Psychiatry. 2001; 179:540-4. https://doi.org/10.1192/bjp.179.6.540
PMID:11731359

78. Zigmond AS, Snaith RP. The hospital anxiety and depression scale. Acta Psychiatr Scand. 1983; 67:361-70.

https://doi.org/10.1111/j.1600-0447.1983.tb09716.x PMID: $\underline{6880820}$

79. Nasreddine ZS, Phillips NA, Bédirian V, Charbonneau S, Whitehead V, Collin I, Cummings JL, Chertkow H. The Montreal Cognitive Assessment, MoCA: a brief screening tool for mild cognitive impairment. J Am Geriatr Soc. 2005; 53:695-9.

https://doi.org/10.1111/j.1532-5415.2005.53221.x PMID:15817019

80. Borland E, Nägga K, Nilsson PM, Minthon L, Nilsson ED, Palmqvist $S$. The Montreal Cognitive Assessment: Normative Data from a Large Swedish Population-Based Cohort. J Alzheimers Dis. 2017; 59:893-901.

https://doi.org/10.3233/JAD-170203

PMID:28697562

81. Stensvold D, Bucher Sandbakk S, Viken H, Zisko N, Reitlo LS, Nauman J, Gaustad SE, Hassel E, Moufack M, Brønstad E, Aspvik NP, Malmo V, Steinshamn SL, et al. Cardiorespiratory Reference Data in Older Adults: The Generation 100 Study. Med Sci Sports Exerc. 2017; 49:2206-15. https://doi.org/10.1249/MSS.0000000000001343 PMID:28598909

82. Gibbons RJ, Balady GJ, Beasley JW, Bricker JT, Duvernoy WF, Froelicher VF, Mark DB, Marwick TH, McCallister BD, Thompson PD Jr, Winters WL, Yanowitz FG, Ritchie JL, et al. ACC/AHA Guidelines for Exercise Testing. A report of the American College of Cardiology/American Heart Association Task Force on Practice Guidelines (Committee on Exercise Testing). J Am Coll Cardiol. 1997; 30:260-311. https://doi.org/10.1016/s0735-1097(97)00150-2 PMID: $\underline{9207652}$

83. Olsson E, Klasson N, Berge J, Eckerström C, Edman A, Malmgren $\mathrm{H}$, Wallin $\mathrm{A}$. White Matter Lesion Assessment in Patients with Cognitive Impairment and Healthy Controls: Reliability Comparisons between Visual Rating, a Manual, and an Automatic Volumetrical MRI Method-The Gothenburg $\mathrm{MCl}$ Study. J Aging Res. 2013; 2013:198471. https://doi.org/10.1155/2013/198471 PMID:23401776

84. Wei K, Tran T, Chu K, Borzage MT, Braskie MN, Harrington MG, King KS. White matter hypointensities and hyperintensities have equivalent correlations with age and CSF $\beta$-amyloid in the nondemented elderly. Brain Behav. 2019; 9:e01457. https://doi.org/10.1002/brb3.1457 
PMID: $\underline{31692294}$

85. Fischl B. FreeSurfer. Neuroimage. 2012; 62:774-81. https://doi.org/10.1016/i.neuroimage.2012.01.021 PMID:22248573

86. Seo SW, Lee JM, Im K, Park JS, Kim SH, Kim ST, Ahn HJ, Chin J, Cheong HK, Weiner MW, Na DL. Cortical thinning related to periventricular and deep white matter hyperintensities. Neurobiol Aging. 2012; 33:1156-67.

https://doi.org/10.1016/i.neurobiolaging.2010.12.003 PMID:21316813

87. Bauer CE, Zachariou V, Seago E, Gold BT. White Matter Hyperintensity Volume and Location: Associations With WM Microstructure, Brain Iron, and Cerebral Perfusion. Front Aging Neurosci. 2021; 13:617947.

https://doi.org/10.3389/fnagi.2021.617947 PMID:34290597

88. Hansen TI, Brezova V, Eikenes L, Håberg A, Vangberg TR. How Does the Accuracy of Intracranial Volume Measurements Affect Normalized Brain Volumes? Sample Size Estimates Based on 966 Subjects from the HUNT MRI Cohort. AJNR Am J Neuroradiol. 2015; 36:1450-6.

https://doi.org/10.3174/ajnr.A4299

PMID:25857759
89. Little RJA. A Test of Missing Completely at Random for Multivariate Data with Missing Values. J Am Stat Assoc. 1988; 83:1198-202. https://doi.org/10.1080/01621459.1988.10478722

90. Twisk J, Bosman L, Hoekstra T, Rijnhart J, Welten M, Heymans M. Different ways to estimate treatment effects in randomised controlled trials. Contemp Clin Trials Commun. 2018; 10:80-5. https://doi.org/10.1016/i.conctc.2018.03.008 PMID:29696162

91. Coffman CJ, Edelman D, Woolson RF. To condition or not condition? Analysing 'change' in longitudinal randomised controlled trials. BMJ Open. 2016; 6:e013096.

https://doi.org/10.1136/bmjopen-2016-013096 PMID:28039292

92. Portney LG, Watkins MP. Foundations of clinical research: applications to practice. 2nd ed. Upper Saddle River, NJ: Prentice Hall; 2000; 768. 


\section{SUPPLEMENTARY MATERIALS}

\section{Supplementary Figure}

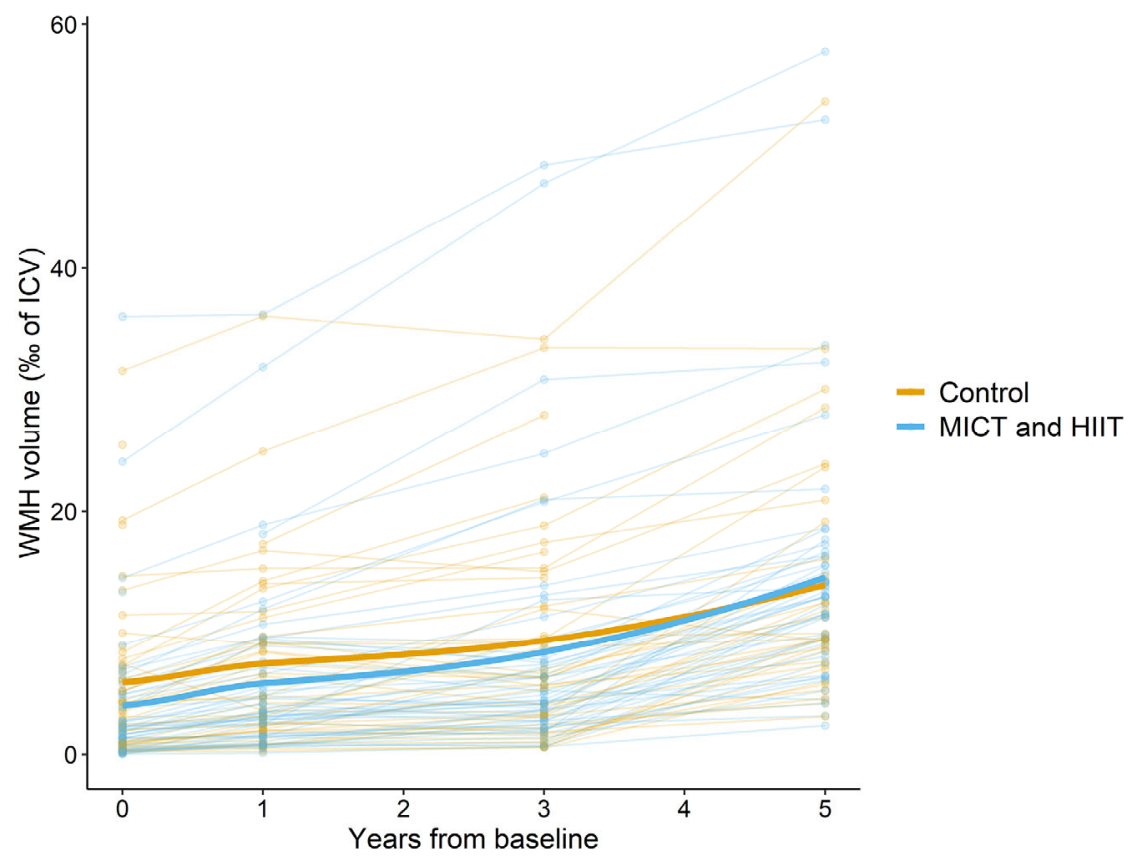

Supplementary Figure 1. Illustration of the interaction effect demonstrated in the linear mixed model investigation (Supplementary Table 1). The mean WMH volume in \% of ICV at baseline, and after one, three, and five years of the intervention in the Control group (in orange) and the combined supervised exercise group (MICT\&HIIT) in blue. Abbreviations: WMH: white matter hyperintensities; ICV: intracranial volume; MICT: moderate-intensity continuous training; HIIT: high-intensity interval training. 


\section{Supplementary Table}

Supplementary Table 1. The effect of the interventions across the five-year intervention period on WMH, PWMH, DWMH and WM-hypo volumes (corrected for ICV) adjusted for age, sex, and baseline outcome values for the two intervention groups combined (MICT and HIIT) compared to the control group.

\begin{tabular}{lccccccccccccccc}
\hline & & WMH & & & PWMH. & & DWMH. & WM-hypo. \\
\hline Predictors & Est. & CI (95\%) & p-value & Est. & CI (95\%) & p-value & Est. & CI (95\%) & p-value & Est. & CI (95\%) & p-value \\
\hline Women & 2.01 & $-1.21,5.22$ & 0.219 & 0.88 & $-1.07,2.82$ & 0.375 & 1.21 & $-0.34,2.75$ & 0.124 & -0.79 & $-1.81,0.24$ & 0.130 \\
Age & 0.26 & $-0.56,1.09$ & 0.528 & 0.46 & $-0.04,0.97$ & 0.073 & -0.17 & $-0.56,0.23$ & 0.404 & 0.29 & $0.02,0.56$ & $\mathbf{0 . 0 3 5}$ \\
Year one & 1.05 & $-0.68,2.79$ & 0.232 & 0.49 & $-0.67,1.65$ & 0.403 & 0.84 & $0.08,1.60$ & $\mathbf{0 . 0 3 0}$ & 0.01 & $-0.69,0.70$ & 0.983 \\
Year three & 2.40 & $-0.51,5.30$ & 0.105 & 1.21 & $-0.62,3.04$ & 0.193 & 1.30 & $-0.04,2.63$ & 0.057 & 0.20 & $-0.83,1.23$ & 0.701 \\
Year five & 7.67 & $3.13,12.21$ & $\mathbf{0 . 0 0 1}$ & 4.57 & $1.76,7.38$ & $\mathbf{0 . 0 0 2}$ & 3.07 & $0.95,5.19$ & $\mathbf{0 . 0 0 5}$ & 0.72 & $-0.81,2.24$ & 0.356 \\
MICT\&HIIT & -1.17 & $-4.39,2.05$ & 0.473 & -0.97 & $-2.93,1.00$ & 0.331 & -0.42 & $-1.96,1.13$ & 0.591 & -0.52 & $-1.63,0.61$ & 0.363 \\
MICT\&HIIT*1-year & 0.08 & $-1.66,1.82$ & 0.931 & 0.05 & $-1.19,1.28$ & 0.943 & -0.15 & $-0.84,0.55$ & 0.680 & 0.31 & $-0.49,1.11$ & 0.444 \\
MICT\&HIIT*3-year & 0.73 & $-1.06,2.51$ & 0.422 & 0.55 & $-0.71,1.81$ & 0.391 & 0.06 & $-0.66,0.76$ & 0.880 & -0.05 & $-0.87,0.77$ & 0.897 \\
MICT\&HIIT*5-year & 1.21 & $-0.61,3.04$ & 0.191 & 1.16 & $0.10,2.22$ & $\mathbf{0 . 0 3 2}$ & -0.18 & $-0.91,0.54$ & 0.620 & -0.44 & $-1.27,0.39$ & 0.300 \\
\hline AIC & & & 2105.5 & & & 1819.4 & & & 1489.8 &
\end{tabular}

There was a significant interaction between year and the exercise interventions combined (MICT and HIIT), this term was therefore kept for final analysis. Other non-significant interaction terms (between sex, age, or the exercise interventions combined [MICT\&HIIT) were removed from the statistical models. Abbreviations: WMH: white matter hyperintensities; PWMH: periventricular WMH; DWMH: deep WMH; WM-hypo: white matter hypointensities; ICV: intracranial volume; Cl: confidence interval; MICT: moderate-intensity continuous training; HIIT: high-intensity interval training; MICT\&HIIT: MICT and HIIT combined into one intervention group; Est.: estimates; AIC: Akaike's information criterion. 